European Journal of Finance, 2010, Volume 16, Number 3, Pages 263-279.

\title{
Size and Book-to-Market Anomalies and Omitted Leverage Risk
}

\author{
Vineet Agarwal \\ (Cranfield University School of Management) \\ and \\ Sunil Poshakwale \\ (Cranfield University School of Management) \\ July 2009
}

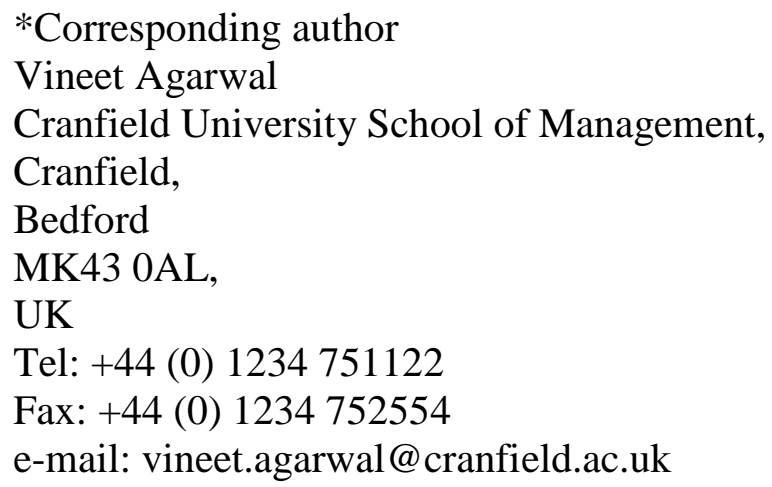




\title{
Size and Book-to-Market Anomalies and Omitted Leverage Risk
}

\begin{abstract}
Ferguson and Shockley (2003) develop a theoretical model and argue that size and book-to-market $(\mathrm{B} / \mathrm{M})$ effects in stock returns derive their cross-sectional explanatory power because they proxy for leverage and financial distress. Using UK data from 1979 to 2006, we provide evidence that the size factor of Fama and French (1993) is indeed proxying for distress risk while their distress factor is capturing leverage risk. However, anomalously low returns and higher exposure of small size and value stocks to the distress factor reduces the expected returns on these stocks and results in larger pricing errors. This leads to poor performance of the Ferguson and Shockley (2003) model in the time-series. Underperformance of distressed stocks casts doubt on the hypothesis that the explanatory power of size and book-to-market factors is due to the omitted debt claims in equity only proxy for market portfolio.
\end{abstract}




\section{Size and Book-to-Market Anomalies and Omitted Leverage Risk}

\section{Introduction}

Higher returns earned by small stocks and high book-to-market (B/M) stocks have been a subject of intense academic enquiry. Majority of asset pricing research attributes this phenomenon to high distress risk of these stocks (see, Chan and Chen, 1991; Fama and French, 1992). Ferguson and Shockley (2003) argue that true equity beta of a firm is a weighted average of its covariance with the economy's equity claims and debt claims. Their theoretical model shows that the usual method of using an equity market index as a proxy for the market portfolio will underestimate true equity betas, and this underestimation is a function of the sensitivity of the firm's equity to the omitted debt claims in the economy. They argue that these estimation errors are more severe for firms with higher leverage and for firms which are distressed. Further, any factor such as size and $\mathrm{B} / \mathrm{M}$ that proxy leverage and distress risk will compensate for underestimated equity betas and would be able to explain the stock returns.

Ferguson and Shockley's (2003) prediction that market betas of distressed stocks are too low and that this underestimation is correlated with leverage and distress risk has following implications: (i) positive CAPM alphas on small size and high B/M stocks observed in empirical studies (e.g. Fama and French, 1993 and 1996) should be positively correlated to leverage and financial distress, (ii) a model with more direct proxies of sensitivity to debt claims such as leverage and distress risk will outperform Fama and French (1993) model, (iii) factor loadings on SMB (the factor mimicking size effect) and HML (the factor mimicking B/M effect) should be positively correlated with the factor loadings on more direct proxies, and (iv) the explanatory power of SMB and 
HML will decline once they are orthogonalised with respect to more direct proxies for leverage and distress risk.

In testing their model, Ferguson and Shockley construct a direct proxy for distress risk using Altman's (1968) z-score. However, the validity of their model and results are questionable. First, whilst their model assumes that the distressed stocks earn higher returns than non-distressed stocks, their own empirical findings as well as those reported in the literature (e.g., Dichev, 1998; Campbell et al., 2008; Agarwal and Taffler, 2008a), point to the contrary. Second, given that they construct their distress factor as the difference between the returns on non-distressed and distressed stocks, distressed stocks should show a lower exposure to their distress factor. However, their finding that distressed stocks show a higher exposure to their distress factor is counterintuitive.

Using UK data from 1979 to 2006, this paper examines whether the observed size and book to market effects in stock returns are driven by estimation errors in equity betas due to omitted debt claims from the equity only market portfolio. We find CAPM alphas are positively correlated to leverage and distress factors suggesting a systematic downward bias in estimated betas of highly leveraged firms and distressed firms. We also find SMB and HML factor loadings are positively correlated to distress and leverage factor loadings respectively suggesting SMB could be proxying for distress risk while HML could be proxying for leverage. We show that negative returns on the distress factor (a common finding in the literature) lead to poor performance of the Ferguson and Shockley (2003) model as compared to the Fama and French (1993) model. This suggests that higher returns on small stocks and high $\mathrm{B} / \mathrm{M}$ stocks are not compensation for higher distress risk. 
The rest of the paper is organized as follows: section 2 explains the theory and method, section 3 explains the data used, section 4 discusses the empirical results, and the concluding section, section 5 summarizes the main conclusions of the study.

\section{Theory and Method}

The theoretical model of Ferguson and Shockley (2003) is quite intuitive. The market portfolio of CAPM can be considered to be composed of two sub portfolios: one with all equity claims in the economy and the other with all debt claims. The covariance of a firm's equity claim with the market portfolio will then be a weighted average of the covariance of the firm's equity claims with the two sub portfolios. Simple algebraic manipulation then shows that the true beta of a firm is:

$$
\beta=\Phi \hat{\beta}_{\mathrm{E}}+\Omega \hat{\beta}_{\mathrm{D}}
$$

Where:

$\hat{\beta}_{\mathrm{E}}=$ Equity beta estimated against equity only market sub portfolio,

$\hat{\beta}_{\mathrm{D}}=$ Debt beta estimated against debt only market sub portfolio,

$\Phi=\frac{\mathrm{E}}{\mathrm{M}} * \frac{\sigma_{\mathrm{E}}^{2}}{\sigma_{\mathrm{M}}^{2}}$

$\Omega=\frac{\mathrm{D}}{\mathrm{M}} * \frac{\sigma_{\mathrm{D}}^{2}}{\sigma_{\mathrm{M}}^{2}}$,

$\mathrm{E}=$ All equity claims,

$\mathrm{D}=$ All debt claims

$\sigma_{\mathrm{E}}^{2}=$ Variance of equity market returns,

$\sigma_{\mathrm{D}}^{2}=$ Variance of debt market returns, and 
$\sigma_{\mathrm{M}}^{2}=$ Variance of market portfolio returns.

Rearranging equation (1) gives (Ferguson and Shockley, 2003:2550):

$$
\hat{\beta}_{\mathrm{E}}=\Phi^{-1}\left(\beta-\Omega \hat{\beta}_{\mathrm{D}}\right)
$$

Equation (2) shows that there are two sources of error in the market beta estimated using the equity only proxy, the scaling error $\left(\Phi^{-1}\right)$ and firm specific error $\left(-\Omega \hat{\beta}_{D}\right)$. The debt beta will be higher for firms with higher leverage and/or higher risk of financial distress and therefore, the estimated equity beta of such firms will be more severely biased downwards. It is important to consider the risk of financial distress as well because given the same leverage, the debt beta (estimated beta) of firms at higher risk of failure will be higher (lower). Downward biased estimated betas will generate lower expected returns leading to upward biased CAPM intercepts. Hence, the first implication of the model is that CAPM intercepts will be positively related to leverage and financial distress.

The firm specific error term also implies that factors that capture leverage and financial distress will provide a correction for the downward bias in estimated equity betas and appear to explain stock returns. Smaller firms are more exposed to risk of failure and hence, SMB may be deriving its explanatory power from its link to financial distress. We can decompose B/M ratio into (Fama and French, 1992:444):

$$
\frac{\mathrm{BVE}}{\mathrm{MVE}}=\frac{\mathrm{BVE}}{\mathrm{BVD}} * \frac{\mathrm{BVD}}{\mathrm{MVE}}
$$

Where:

$\mathrm{BVE}=$ Book value of equity,

MVE = Market value of equity, and

BVD $=$ Book value of debt 
The first term on RHS of equation (3) measures book leverage and the second term measures market leverage. Hence, HML may be deriving its explanatory power from its link to financial distress. If SMB and HML are deriving their explanatory power because they are capturing leverage and financial distress effects, then we would expect: (a) improved explanatory power (relative to the Fama and French (1993) three factor model) for a model with factors more directly related to leverage and financial distress, and (b) high correlation between the factor loadings on SMB and HML and those on these more direct proxies. We would also expect that inclusion of more direct proxies will reduce the role of SMB and HML in explaining stock returns. ${ }^{1}$

To test the explanatory power of various factors over time, we use different specifications of the Fama and French (1993) three-factor model augmented by the distress and leverage factors:

$\mathrm{R}_{\mathrm{it}}-\mathrm{R}_{\mathrm{Ft}}=\beta_{1}+\beta_{\mathrm{RMRF}} \mathrm{RMRF}_{\mathrm{t}}+\beta_{\mathrm{SMB}} \mathrm{SMB}_{\mathrm{t}}+\beta_{\mathrm{HML}} \mathrm{HML}_{\mathrm{t}}+\beta_{\mathrm{NMP}} \mathrm{NMP}_{\mathrm{t}}+\beta_{\mathrm{DE}} \mathrm{DE}_{\mathrm{t}}+\varepsilon_{\mathrm{it}}$

where:

$\mathrm{R}_{\mathrm{it}}$ is the value weighted return on portfolio i during month $\mathrm{t}$,

$\mathrm{R}_{\mathrm{Ft}}$ is the 1-month T-bill rate at the beginning of month $\mathrm{t}$,

$\mathrm{RMRF}_{\mathrm{t}}$ is the difference between the value-weighted return of all the stocks in the sample during month $\mathrm{t}$ and $\mathrm{R}_{\mathrm{Ft}}$,

$\mathrm{SMB}_{\mathrm{t}}$ is the return on the mimicking portfolio for the size factor during month $\mathrm{t}$, $\mathrm{HML}_{\mathrm{t}}$ is the return on the mimicking portfolio for the $\mathrm{B} / \mathrm{M}$ factor during month $\mathrm{t}$, $\mathrm{NMP}_{\mathrm{t}}$ is the return on the mimicking portfolio for the $\mathrm{z}$-score factor during month $\mathrm{t}$, $\mathrm{DE}_{\mathrm{t}}$ is the return on the mimicking portfolio for the leverage factor during month $\mathrm{t}$, and 
$\varepsilon_{\mathrm{it}}$ is a mean-zero stochastic error term.

If higher returns on small stocks and high $\mathrm{B} / \mathrm{M}$ stocks are due to their higher distress risk, we would expect such stocks to load more heavily on NMP and DE factors, and that inclusion of these factors would either drive out SMB and HML (if NMP and DE are perfect proxies for distress risk) or at least reduce their explanatory power (if NMP and DE are imperfect proxies for distress risk). In addition, the three factor model of Ferguson and Shockley (2003) should produce lower pricing errors than both, the CAPM and the Fama-French three factor model, and the five factor model should produce smaller pricing errors than both the three factor models.

We use the Gibbons et al. (1989) F-statistic to test whether the regression intercepts for the test assets are jointly zero. Gibbons et al. (1989) show that:

$$
[(\mathrm{T} / \mathrm{N}) *(\mathrm{~T}-\mathrm{N}-\mathrm{L}) /(\mathrm{T}-\mathrm{N}-1)] *\left[1+\left(\overline{\mathbf{r}}_{\mathrm{P}}^{\prime} \hat{\mathbf{\Omega}}^{-1} \overline{\mathbf{r}}_{\mathrm{P}}\right)\right]^{-1} *\left(\hat{\boldsymbol{\delta}}_{0}^{\prime} \hat{\boldsymbol{\Sigma}}^{-1} \hat{\boldsymbol{\delta}}_{0}\right)
$$

is approximately F-distributed with $\mathrm{N}$ numerator and T-N-L denominator degrees of freedom.

Where:

$\mathrm{T}=$ Number of months,

$\mathrm{N}=$ Number of portfolios,

$\mathrm{L}=$ Number of factors,

$\overline{\mathbf{r}}_{\mathrm{P}}=\mathrm{LX} 1$ column vector of sample means for each of the factors

$\hat{\mathbf{\Omega}}_{\mathrm{P}}=$ LXL covariance matrix of the factors

$\hat{\boldsymbol{\delta}}_{0}=\mathrm{NX} 1$ column vector of regression intercepts, and

$\hat{\boldsymbol{\Sigma}}=\mathrm{NXN}$ covariance matrix of residuals of $\mathrm{N}$ regressions. 


\section{Data}

\subsection{Sample Selection}

The study covers all non financial UK stocks listed on the London Stock Exchange (LSE) at any time during the period $1979-2005 .^{2}$ If a stock changes industry or exchange of listing, it enters the respective portfolio only after it has been listed on the London Stock Exchange or is classified as non-financial stock for 24 months. If the exchange of listing or industry changes during the holding period, returns after the change are deleted and the stock is assumed to earn the portfolio return. To be included in the sample, stocks are required to meet three additional conditions:

(1) they should have positive book value because interpretation of negative bookto-market ratios is problematic,

(2) they should have been listed for at least 24 months before the portfolio formation date to ensure only post-listing accounting information is used; and

(3) they should have been traded in at least 9 of the 12 months subsequent to portfolio formation to circumvent any potential thin trading problem. This rule does not apply to stocks that do not survive the holding period.

The final sample consists of 2,521 stocks and a total of 25,379 firm years. The yearly number of stocks in the sample ranges from a minimum of 566 in 2005 to a maximum of 1,229 in 1981.

\subsection{Data}

Similar to Ferguson and Shockley (2003), we use z-score as a proxy for distress risk except that the z-scores are derived using the following UK-based model of Taffler (1983 and 1984): ${ }^{3}$ 


$$
\mathrm{z}=3.20+12.18 * \mathrm{x}_{1}+2.50 * \mathrm{x}_{2}-10.68 * \mathrm{x}_{3}+0.029 * \mathrm{x}_{4}
$$

where

$\mathrm{x}_{1}=$ profit before tax $(\mathrm{PBT}) /$ current liabilities,

$\mathrm{x}_{2}=$ current assets/total liabilities,

$\mathrm{x}_{3}=$ current liabilities/total assets, and

$\mathrm{x}_{4}=$ no-credit interval computed as (quick assets - current

liabilities)/ ((sales - PBT - depreciation)/365).

Using this bankruptcy model, a firm with a negative $\mathrm{z}$ score has a financial profile more similar to previously bankrupt firms and thus carries bankruptcy risk, whereas firms with positive z score do not carry bankruptcy risk. Out of a total of 207 failures in our sample, only 13 firms had a positive z-score. Since the model was developed in 1977, the derived z-scores are completely out-of-sample and thus free of any hindsight bias.

The accounting data required for $\mathrm{z}$-score, $\mathrm{B} / \mathrm{M}$ ratio and $\mathrm{D} / \mathrm{E}$ ratio computations are collected from the Thomson Financial Company Analysis, EXSTAT, MicroEXSTAT and DATASTREAM databases in that order. The B/M ratio of each stock is computed as book value of equity (excluding preference capital) plus deferred taxes less minority interests divided by the market capitalization at the time of portfolio formation. The D/E ratio is computed as the ratio of total liabilities to market capitalization at the time of portfolio formation. To ensure that the required accounting information is available at the time of portfolio formation, a five month lag between the fiscal year end date and the reporting date is assumed. For example, for the portfolio formed on $30^{\text {th }}$ September, ${ }^{4}$ book value of equity and z-score are derived from the latest available financial statements with fiscal year-end on or before April $30^{\text {th }}$. 
Monthly stock returns, market capitalizations, exchange listing and stock exchange industrial classifications are collected from the London Business School London Share Price Database (LSPD). The risk free rates (1 month T-bill rates) are collected from DATASTREAM. The list of firm failures is compiled from LSPD (codes 7, 16 and 20), the Stock Exchange Official Yearbook, published by Waterlow Specialist Information Publishing, and CGT Capital Losses published by FT Interactive.

\subsection{Test assets}

Our test assets comprise 25 size and B/M portfolios formed in the same way as in Fama and French (1993). All eligible stocks are ranked on market capitalization on $30^{\text {th }}$ September of year $t$ and sorted into five portfolios with equal numbers of stocks. Stocks are independently ranked on $\mathrm{B} / \mathrm{M}$ ratio on $30^{\text {th }}$ September of year $\mathrm{t}$ and sorted into five portfolios of equal numbers of stocks. Twenty-five size and $\mathrm{B} / \mathrm{M}$ portfolios are formed at the intersections of the break-points. Value weighted monthly returns are then computed for each portfolio from October of year $t$ to September of year $t+1$. The procedure is repeated on $30^{\text {th }}$ September of each year from 1979 to 2005 . The last monthly return for failed stocks is set equal to $-100 \% .^{5}$ Stocks that are delisted during the holding period for reasons other than failure are assumed to earn the reference portfolio returns for the remainder of the period.

\subsection{Factor returns}

SMB and HML are constructed as in Fama and French (1993). Specifically, on $30^{\text {th }}$ September each year from 1979 to 2005, all eligible stocks are ranked on market capitalization and sorted into two portfolios with equal numbers of stocks. Stocks are 
independently ranked on $\mathrm{B} / \mathrm{M}$ and sorted into three portfolios, the low $\mathrm{B} / \mathrm{M}$ portfolio (L) with bottom $30 \% \mathrm{~B} / \mathrm{M}$ stocks, the high $\mathrm{B} / \mathrm{M}$ portfolio $(\mathrm{H})$ with highest $30 \% \mathrm{~B} / \mathrm{M}$ stocks, the medium B/M portfolio (M) with middle $40 \% \mathrm{~B} / \mathrm{M}$ stocks. Six size and B/M portfolios are then formed at the intersections of the break-points. Value weighted monthly returns are computed for each portfolio from October of year $t$ to September of year $t+1$. The factor mimicking the returns related to size (SMB) is the difference between equally-weighted average of returns on the three small portfolios and the three large portfolios. The factor mimicking the returns related to $\mathrm{B} / \mathrm{M}$ (HML) is the difference between equally-weighted average of returns on the two high $\mathrm{B} / \mathrm{M}$ portfolios and the two low $\mathrm{B} / \mathrm{M}$ portfolios.

The factor mimicking the returns on distress factor (NMP) and leverage factor (DE) are constructed as follows: on the $30^{\text {th }}$ of September of each year, all stocks in the portfolio are ranked on z-score and grouped into two portfolios, one with negative zscore stocks $(\mathrm{N})$ and the other with positive $\mathrm{z}$-score stocks $(\mathrm{P})$. Independently, the stocks are sorted on their debt-equity ratio and grouped into three portfolios, one with lowest $30 \%$ (L), one with highest $30 \%(\mathrm{H})$ and one with middle $40 \%(\mathrm{M})$ of the stocks. Six portfolios are then formed at the intersections of the two z-score and three leverage portfolios. Monthly value weighted returns are calculated on each of the portfolios and the portfolios are rebalanced at the end of each September. Factor NMP is constructed as the difference between the equally weighted average of returns on the three negative Z-score portfolios and the three positive z-score portfolios. ${ }^{6}$ Factor DE is constructed as the difference between the equally weighted average of returns on the two highest leverage portfolios and the two lowest leverage portfolios. ${ }^{7}$ 


\section{Results}

\subsection{Summary Statistics}

Table 1 presents the summary statistics for factor returns. Panel A shows that during the sample period (October 1979 to September 2006), the average monthly UK return on the market factor $(\mathrm{RMRF})$ is $0.46 \%(\mathrm{t}=1.87)$, on size factor $(\mathrm{SMB})$ it is $0.22 \%(\mathrm{t}=$ $1.00)$, on $\mathrm{B} / \mathrm{M}$ factor $(\mathrm{HML})$ it is $0.44 \%(\mathrm{t}=2.44)$, on distress factor $(\mathrm{NMP})$ the return is $-0.35 \%(t=-2.66)$ and on leverage factor $(D / E)$ it is $0.65 \%(t=3.14)$. Panel B of table 1 shows that the distress factor returns are negatively correlated to HML $(r=-0.23)$ and positively correlated to $\mathrm{SMB}(\mathrm{r}=0.37)$. It also shows that the leverage factor $(\mathrm{DE})$ is orthogonal to SMB $(r=0.00)$ but is positively correlated to HML $(r=0.53)$. These result provide a preliminary evidence that SMB may be related to distress risk, while HML appears to proxy leverage. Although our results contradict Ferguson and Shockley $(2003)^{8}$ they are consistent with other studies (see e.g., Dichev, 1998 and Agarwal and Taffler, 2008a) which do not find positive correlation between $\mathrm{B} / \mathrm{M}$ ratio and $\mathrm{z}$ score proxying for the distress risk.

\section{Table 1 here}

Table 2 presents the main characteristics of the six z-score and leverage portfolios used for constructing NMP and DE factors. As expected, results show that the failure rate is highest for firms with high leverage and negative z-score (panel A) and high leverage firms are smaller and have high $\mathrm{B} / \mathrm{M}$ ratios (panels $\mathrm{B}$ and $\mathrm{C}$ ). The relation between $\mathrm{Z}$-score and leverage is clear from panel $\mathrm{F}$ where very few firms have low $\mathrm{D} / \mathrm{E}$ ratio and negative z-score while a disproportionately large number of negative z-score firms have high $\mathrm{D} / \mathrm{E}$ ratio. Panel $\mathrm{G}$ shows that negative $\mathrm{z}$-score firms underperform 
across all three leverage portfolios while high leverage firms outperform across both negative and positive z-score portfolios.

\section{Table 2 here}

Table 3 presents salient features of the 25 size and $\mathrm{B} / \mathrm{M}$ portfolios used as test assets. Panel A shows that the failure rates for smallest size quintile is much higher than that for other quintiles and the failure rate decreases monotonically with increase in size. It also shows that whilst highest $\mathrm{B} / \mathrm{M}$ quintile has highest failure rates, the relation between $\mathrm{B} / \mathrm{M}$ and failure rate is not monotonic, both lowest and highest $\mathrm{B} / \mathrm{M}$ quintiles have higher failure rates for the three smaller size portfolios. ${ }^{9}$ Z-scores in panel B and leverage ratios in panel $\mathrm{C}$ closely reflect the pattern in failure rates. The table provides preliminary evidence of a strong relation of failure rates with size, z-score, and leverage but a weak relation with $\mathrm{B} / \mathrm{M}$ ratio. ${ }^{10}$

\section{Table 3 here}

\subsection{Time-Series Regressions}

In this sub-section, we report the results of time series regressions on the 25 size and $\mathrm{B} / \mathrm{M}$ portfolios using equation (4). These regressions provide a test of whether the leverage and distress factors have a role in explaining stock returns.

\subsubsection{Single Factor Model, Three Factor Model, and Stock Returns}

Table 4 presents the results of time series regressions on 25 size and $\mathrm{B} / \mathrm{M}$ portfolios with the market factor as the only explanatory variable. The F-test of Gibbons et al. (1989) rejects the null hypothesis that the intercepts are jointly zero at the $1 \%$ level of significance $^{11}$ confirming the inability of the CAPM to correctly price small size portfolios and high $\mathrm{B} / \mathrm{M}$ portfolios. 
Consistent with the predictions of Ferguson and Shockley (2003), relatively distressed portfolios (small size and high $\mathrm{B} / \mathrm{M}$ ) have positive intercepts and the pattern of intercepts mirrors the pattern in $\mathrm{z}$-scores $(\mathrm{r}=-0.73)$, leverage ratios $(\mathrm{r}=0.69)$ and failure rates $(r=0.67) .{ }^{12}$ This provides evidence that the CAPM betas estimated using equity only market portfolio are more severely underestimated for distressed portfolios.

\section{Table 4 here}

Table 5 presents the results for the Fama and French (1993) three-factor model on 25 portfolios show that inclusion of SMB and HML in the pricing equation improves the pricing of small size and high $\mathrm{B} / \mathrm{M}$ portfolios by increasing their market betas and higher loadings on SMB and HML. This leads to higher expected returns and statistically insignificant intercepts for these portfolios. The GRS test is unable to reject the null hypothesis of intercepts being jointly zero at the $5 \%$ level of significance. ${ }^{13}$

\section{Table 5 here}

\subsubsection{Distress Factor and Stock Returns}

The theoretical model of Ferguson and Shockley (2003) predicts that addition of distress and leverage factors to the CAPM will provide a better description of stock returns than the Fama and French (1993) model. Accordingly, inclusion of these factors should increase the expected returns on relatively distressed stocks (i.e. small stocks and high $\mathrm{B} / \mathrm{M}$ stocks), and thus reduce the pricing errors observed in table 4 .

Table 6 presents the results when NMP and DE are added to RMRF as additional explanatory variables. We find that consistent with higher distress risk of small stocks, 
small portfolios load heavily on NMP while heavy loadings of value portfolios on DE show high leverage risk of high $\mathrm{B} / \mathrm{M}$ stocks. However, the three factor model of Ferguson and Shockley (2003) results in higher pricing errors ${ }^{14}$ and does not outperform Fama and French (1993) three factor model. This is mainly due to two reasons: (i) addition of NMP and DE factors reduces the market beta for smaller stocks and higher $\mathrm{B} / \mathrm{M}$ stocks thereby reducing the expected returns on these stocks, and (ii) the average return on NMP is negative, so higher loading on this factor reduces the expected returns for small and high B/M portfolios even further. Higher loadings on the DE factor are not able to offset the effect of reduced exposure to the market factor and negative NMP returns. The evidence is consistent with that of Agarwal and Taffler (2008a) and Campbell et al. (2008) that whilst the distress factor helps in explaining the variation in stock returns, anomalously lower returns on distressed stocks increase the pricing errors.

\section{Table 6 here}

However, there is some support for the model. Consistent with the hypothesized inverse relation between size and distress risk, the coefficient for NMP decreases monotonically with size, and the coefficients on NMP in table 6 and on SMB in table 5 are highly correlated (significant Spearman rank correlation $=0.97$ ). The NMP and HML coefficients are orthogonal to each other (insignificant Spearman rank correlation $=-0.01$ ) indicating lack of relation between $\mathrm{B} / \mathrm{M}$ factor and distress factor. The loadings on leverage factor (DE) on the other hand, have a lower correlation with loadings on SMB (insignificant Spearman rank correlation $=0.36$ ) but are highly correlated to the loadings on HML (significant Spearman rank correlation $=0.74$ ), indicating that the $\mathrm{B} / \mathrm{M}$ factor is capturing the leverage effect in stock returns. 
Finally, the theoretical model of Ferguson and Shockley (2003) predicts that if SMB and HML are deriving their explanatory power due to their correlations with the omitted distress and leverage factors, introduction of these factors will at least reduce the contribution of SMB and HML. Their model also suggests that increased expected returns on relatively distressed stocks will reduce the pricing errors for such stocks. To examine this without the potential complication due to significant correlations between Fama and French (1993) and Ferguson and Shockley (2003) factors, and to gain a clearer understanding of the role of distress and leverage factors in SMB and HML, we orthogonalize NMP and DE with respect to SMB and HML using the following regressions:

$$
\mathrm{NMP}_{\mathrm{t}}=\alpha+\beta_{1} \mathrm{SMB}_{\mathrm{t}}+\beta_{2} \mathrm{HML}_{\mathrm{t}}+\varepsilon_{\mathrm{t}}
$$

and

$$
\mathrm{DE}_{\mathrm{t}}=\alpha+\beta_{1} \mathrm{SMB}_{\mathrm{t}}+\beta_{2} \mathrm{HML}_{\mathrm{t}}+\varepsilon_{\mathrm{t}}
$$

Orthogonalised distress factor $(\operatorname{NMP}(\mathrm{O}))$ is then the sum of intercept and residuals in (7) and orthogonalised leverage factor $(\mathrm{DE}(\mathrm{O}))$ is the sum of intercept and residuals in (8). Similarly, $\mathrm{SMB}(\mathrm{O})$ is estimated as the sum of residuals and intercept from the regression of SMB against $\mathrm{NMP}$ and $\mathrm{DE}$ and $\operatorname{HML}(\mathrm{O})$ is estimated as the sum of residuals and intercept from the regression of HML against NMP and DE.

Table 7 panel A presents the results of the Fama and French (1993) 3-factor model augmented by distress and leverage factors orthogonalised with respect to SMB and HML. The results show that the exposure to orthogonalised NMP is much lower than the exposure to unorthogonalised NMP in table 6 demonstrating that SMB and NMP may be proxying for a common state variable. Similarly, exposure to orthogonalised DE being much lower than the exposure to unorthogonalised DE in table 6 suggests that 
HML and DE may be related to some common state variable. Panel B shows that when we orthogonalise SMB and HML with respect to NMP and DE, the orthogonalised variables remain very important in explaining the difference between portfolio returns and risk free rate over time. As in table 6, addition of NMP and DE leads to larger pricing errors and rejection of the null hypothesis of all intercepts being jointly zero at the $1 \%$ level of significance.

\section{Table 7 here}

In summary, our results in table 7 show that HML contains most of the information in the leverage factor which is consistent with Fama and French (1992) who also find that $\mathrm{B} / \mathrm{M}$ subsumes market leverage information in stock returns. Further, consistent with evidence of Dichev (1998) who report lack of any relation between B/M and z scores, we find that HML and NMP do not contain common information. However, at least in the time-series, HML seems to carry additional information since it remains statistically significant even after being orthogonalised with respect to NMP and DE. SMB contains a lot of common information with the distress factor but both, SMB and NMP carry incremental information as well. However, contrary to the predictions of Ferguson and Shockley's model but consistent with their own empirical evidence, distress and leverage factors do not improve the explanatory power of the model, primarily due to positive loadings on NMP leading to reduced expected returns for small size and high $\mathrm{B} / \mathrm{M}$ portfolios.

\subsubsection{Summary of results}

Table 8 presents the summary statistics for the different specifications of equation (4) tested in subsections 4.2.1 and 4.2.2. It shows that the three factor model of Ferguson 
and Shockley (2003) has higher average and absolute average pricing errors $(0.47 \%$ and $0.50 \%$ respectively) than the single factor CAPM $(0.39 \%$ and $0.42 \%$ respectively) and the three factor Fama and French (1993) model (0.06\% and $0.18 \%$ respectively). The variation in pricing errors for the Ferguson and Shockley (2003) three factor model $(0.63 \%)$ is also higher than that for CAPM $(0.51 \%)$ and for the Fama and French (1993) three factor model (0.24\%). In fact, the Fama and French (1993) three factor model outperforms not only the CAPM and the Ferguson and Shockley (2003) three factor models, it also has average pricing errors that are lower than those for the expanded five factor models with orthogonalised factors.

\section{Table 8 here}

Overall, the comparative performance of competing models in terms of pricing the test assets is not supportive of the theoretical predictions of Ferguson and Shockley's model.

\section{Conclusions}

Ferguson and Shockley (2003) develop a model that provides theoretical justification for explaining the observed size and book-to-market $(B / M)$ effects in stock returns to the omitted debt claims in the equity only proxy for the market portfolio. In this paper, using UK data, we test the predictions of their model and find mixed results. Consistent with their prediction that the CAPM betas are systematically underestimated for distressed firms and those with higher leverage, we find CAPM alphas have a strong positive correlation with both distress risk and leverage. High correlations between the loadings on the distress and leverage factors with loadings on SMB and HML respectively are also consistent with their predictions as they suggest that SMB and HML could be acting as proxies for distress risk and leverage. 
However, we find no evidence that their model outperforms the Fama and French (1993) model. In fact, we find that anomalously low returns on the NMP factor leads to larger, not smaller, pricing errors. Our results also show that both SMB and HML carry additional information to that contained in NMP and DE and vice-versa. One possible explanation for this result is that both SMB and NMP are imperfect proxies for distress risk and DE and HML are imperfect proxies for leverage and hence they retain incremental explanatory power after orthogonalisation. The expanded five factor model with both, Fama-French and Ferguson-Shockley factors has marginally superior explanatory power (represented by slightly higher adjusted $\mathrm{R}^{2}$ ) but produces larger pricing errors, again due to anomalously low returns on the distress factor.

In summary, while on one hand, our results are generally consistent with the predictions of Ferguson and Shockley (2003) model that SMB and HML proxy for distress and leverage risk respectively, on the other hand, the results are confounded by counter-intuitive negative returns on the distress factor. Lower returns on distressed stocks are both pervasive and puzzling. Campbell et al. (2008) and Agarwal and Taffler (2008a), offer inter alia, market underreaction and market microstructure explanations. The results here and those in previous literature cast doubt on the hypothesis that the Fama and French (1993) factors represent the correction for underestimated market betas using an equity only proxy for the market portfolio. 


\section{Notes:}

1 Even if SMB and HML derive their explanatory power only from their relation with leverage and distress, they may still not be subsumed by more direct proxies if the later are also imperfect. In this case, SMB and HML may capture residual effects and remain significant.

2 Secondary and foreign stocks, financials (including property) and mining finance, and stocks traded on the Unlisted Securities Market, Alternative Investment Market, Third Market, or Over-the-Counter Market are excluded.

3 Agarwal and Taffler (2008b) show that the predictive ability of this model is at least as good as that of alternative contingent claims approach.

4 September $30^{\text {th }}$ rather than June $30^{\text {th }}$ is chosen as the portfolio formation date because unlike in the US, the UK year-ends are more diffused. While $37 \%$ of the sample stocks have December year-ends, about the same number of stocks have year-ends between January and April with approximately $22 \%$ of the stocks having March year-ends.

5 This treatment is consistent with that of Vassalou and Xing (2004) and Agarwal and Taffler (2008a). In the UK, it is very rare for shareholders to receive anything once the firm goes into bankruptcy process.

6 This is consistent with the spirit of Fama and French factors since it is constructed as the difference in returns on high risk and low risk portfolios.

7 We use double sort for NMP and DE because financial distress risk and leverage are not independent. In our sample, while about $50 \%$ of the high leverage stocks have negative z-scores, only about $10 \%$ of the low leverage stocks have negative z-scores (see table 2, panel F). However, we have repeated our tests using factor mimicking portfolios based on single sorts and the results are qualitatively the same. The results are not reported here to save space and are available from the first author.

8 Ferguson and Shockley find that while the distress factor is positively correlated to HML, it is negatively correlated with SMB.

9 The failure rates for the two largest size portfolios are uninformative as the largest $40 \%$ of the stocks only have $6 \%$ (14) of the failures. 
${ }_{10}$ Spearman rank correlation of failure rates with size is -0.84 , with $\mathrm{z}$-score it is -0.68 and with $\mathrm{D} / \mathrm{E}$ it is 0.56 (all significant at the $1 \%$ level) while with $\mathrm{B} / \mathrm{M}$, it is 0.26 and not significant at the $5 \%$ level. The results are not tabulated to save space.

11 See Flectcher (2001) who finds similar results for UK data.

12 The corresponding Spearman rank correlations are $-0.74,0.81$ and 0.67 respectively.

13 Our results differ from Fletcher (2001) who uses equally weighted portfolios.

${ }^{14}$ GRS F test rejects the null hypothesis of all intercepts being jointly zero at the $1 \%$ level of significance. 


\section{References}

Agarwal, V., and Taffler R. (2008) Does financial distress drive the momentum anomaly?, Financial Management, 37, pp.461-484.

Agarwal, V., and Taffler R. (2008) Comparing the performance of market-based and accounting-based bankruptcy prediction models, Journal of Banking and Finance, 32, pp.1541-1551.

Altman, E.I. (1968) Financial ratios, discriminant analysis and the prediction of corporate bankruptcy, Journal of Finance, 23, pp. 589-609.

Chan, K.C. and Chen N. (1991) Structural and return characteristics of small and large stocks, Journal of Finance, 46, pp. 1467-1484.

Campbell, J.Y., Hilscher J. and Szilagyi J. (2008) In search of distress risk, Journal of Finance, 63, pp.2899-2939.

Dichev, I.D. (1998) Is the risk of bankruptcy a systematic risk?, Journal of Finance, 53, pp. 1131-1147.

Fama, E.F. and MacBeth J. D. (1973) Risk, return, and equilibrium: empirical tests, Journal of Political Economy, 81, pp. 607-636.

Fama, E.F. and French K. R. (1992) The cross-section of expected stock returns, Journal of Finance, 47, pp. 427-465.

(1993) Common risk factors in the returns on stocks and bonds, Journal of Financial Economics, 33, pp. 3-56.

(1996) Multifactor explanations of asset pricing anomalies, The Journal of Finance, 51, pp. 55-84.

Ferguson, M.F. and Shockley R.L. (2003) Equilibrium 'anomalies', Journal of Finance, 58, pp. 2549-2580. 
Fletcher, J. (2001) An examination of alternative factor models in UK stock returns, Review of Quantitative Finance and Accounting, 16, pp. 117-130.

Gibbons, M., Ross, S. and Shanken, J. (1989) A test of the efficiency of a given portfolio, Econometrica 57, pp.1121-1152.

Jagannathan, R. and Wang, Z. (1998) An asymptotic theory for estimating beta-pricing models using cross-sectional regression, Journal of Finance, 53(4), pp.1285-1309.

Shanken, J. (1992) On the estimation of beta-pricing models, Review of Financial Studies, 5, pp.1-33.

Shanken, J. and G. Zhou (2007) Estimating and testing beta-pricing models: alternative methods and their performance in simulations, Journal of Financial Economics, 84, pp. 40-86.

Taffler, R.J. (1983) The assessment of company solvency and performance using a statistical model, Accounting and Business Research, 15, pp. 295-307.

Taffler, R.J., (1984) Empirical models for the monitoring of UK corporations, Journal of Banking and Finance, 8, pp. 199-227.

Vassalou, M. and Xing Y. (2004) Default risk in equity returns, Journal of Finance, 59, pp. 831-868. 
Table 1: Summary statistics of factor returns

\section{Panel A. Summary statistics for explanatory variables}

\begin{tabular}{lrr}
\hline & Mean & t \\
RMRF & 0.46 & 1.87 \\
SMB & 0.22 & 1.00 \\
HML & 0.44 & 2.44 \\
NMP & -0.35 & -2.66 \\
DE & 0.65 & 3.14 \\
\hline
\end{tabular}

\begin{tabular}{|c|c|c|c|c|}
\hline \multicolumn{5}{|c|}{ Panel B. Correlations between factor returns } \\
\hline & RMRF & SMB & HML & NMP \\
\hline SMB & $-0.23 *$ & & & \\
\hline HML & -0.09 & $-0.25 *$ & & \\
\hline NMP & $0.23^{*}$ & $0.37 *$ & $-0.23 *$ & \\
\hline DE & -0.09 & 0.00 & $0.53 *$ & $-0.54 *$ \\
\hline
\end{tabular}

* indicates statistical significance at the 0.05 level

RMRF is the difference between value-weighted returns of all stocks in the analysis and 1-month T-Bill rate, SMB is the factor mimicking size effect, and HML is the factor mimicking $\mathrm{B} / \mathrm{M}$ effect in stock returns. NMP is the factor mimicking $\mathrm{z}$-score effect (distress factor) while DE is the factor mimicking D/E effect (leverage factor). All the portfolios are rebalanced at the end of September each year from 1979 to 2005. Negative B/M stocks are excluded. The last monthly return for failed stocks is set equal to $-100 \%$. 
Table 2: Summary statistics for z-score and leverage portfolios

\begin{tabular}{|c|c|c|c|}
\hline & \multicolumn{3}{|c|}{ Debt-Equity } \\
\hline & Low & Medium & High \\
\hline \multicolumn{4}{|c|}{ Panel A. Failure rates (\%) } \\
\hline $\mathbf{Z}<\mathbf{0}$ & 1.94 & 1.21 & 4.12 \\
\hline $\mathbf{Z}>\mathbf{0}$ & 0.07 & 0.05 & 0.11 \\
\hline \multicolumn{4}{|c|}{ Panel B. Market capitalization (\#m) } \\
\hline $\mathbf{Z}<\mathbf{0}$ & 588.3 & 661.7 & 298.7 \\
\hline $\mathbf{Z}>\mathbf{0}$ & 790.4 & 737.8 & 383.0 \\
\hline \multicolumn{4}{|c|}{ Panel C. Book-to-Market } \\
\hline $\mathbf{Z}<\mathbf{0}$ & 0.34 & 0.62 & 1.52 \\
\hline $\mathbf{Z}>\mathbf{0}$ & 0.53 & 0.90 & 1.90 \\
\hline \multicolumn{4}{|c|}{ Panel D. Z-Score } \\
\hline $\mathbf{Z}<\mathbf{0}$ & -3.31 & -2.53 & -3.05 \\
\hline $\mathbf{Z}>\mathbf{0}$ & 9.34 & 4.93 & 3.08 \\
\hline \multicolumn{4}{|c|}{ Panel E. Debt-Equity } \\
\hline $\mathbf{Z}<\mathbf{0}$ & 0.28 & 0.87 & 3.28 \\
\hline $\mathbf{Z}>\mathbf{0}$ & 0.26 & 0.78 & 2.35 \\
\hline \multicolumn{4}{|c|}{ Panel F. Number of stocks } \\
\hline $\mathbf{Z}<\mathbf{0}$ & 25 & 71 & 142 \\
\hline $\mathbf{Z}>\mathbf{0}$ & 257 & 307 & 140 \\
\hline \multicolumn{4}{|c|}{ Panel G. Monthly value-weightedreturns (\%) } \\
\hline $\mathbf{Z}<\mathbf{0}$ & 0.87 & 1.25 & 1.48 \\
\hline $\mathbf{Z}>\mathbf{0}$ & 1.24 & 1.48 & 1.92 \\
\hline
\end{tabular}

The six z-score and leverage portfolios are formed as follows: on the $30^{\text {th }}$ of September of each year, all stocks in the portfolio are ranked on $\mathrm{z}$-score and grouped into two portfolios, one with negative $\mathrm{z}$-score stocks $(Z<0)$ and the other with positive $\mathrm{z}$-score stocks $(Z>0)$. Independently, the stocks are sorted on their debt-equity ratio and grouped into three portfolios, one with lowest 30\% (Low), one with highest 30\% (High) and one with middle $40 \%$ (Medium) of the stocks. Six portfolios are then formed at the intersections of the two z-score and three leverage portfolios. Panels A to G report the time-series averages over the sample period. 
Table 3: Summary statistics for 25 size and B/M portfolios

\begin{tabular}{cccccc}
\hline Panel A. Failure rates (\%) \\
\hline & \multicolumn{5}{c}{ Book-to-Market } \\
\cline { 2 - 6 } & Low & $\mathbf{2}$ & $\mathbf{3}$ & $\mathbf{4}$ & High \\
\hline Small & 2.89 & 3.17 & 1.42 & 0.90 & 3.56 \\
$\mathbf{2}$ & 0.81 & 0.49 & 0.39 & 0.67 & 1.02 \\
$\mathbf{3}$ & 0.68 & 0.17 & 0.43 & 0.49 & 1.24 \\
$\mathbf{4}$ & 0.14 & 0.22 & 0.28 & 0.00 & 0.25 \\
Big & 0.06 & 0.08 & 0.09 & 0.00 & 0.57 \\
\hline
\end{tabular}

\begin{tabular}{cccccc}
\hline Panel B. Z-scores & \multicolumn{5}{c}{ Book-to-Market } \\
\cline { 2 - 6 } & Low & $\mathbf{2}$ & $\mathbf{3}$ & $\mathbf{4}$ & High \\
\hline Small & -0.71 & 1.90 & 2.99 & 3.53 & 2.49 \\
$\mathbf{2}$ & 1.98 & 4.11 & 4.11 & 3.78 & 2.70 \\
$\mathbf{3}$ & 4.24 & 4.66 & 4.69 & 3.89 & 2.91 \\
$\mathbf{4}$ & 4.63 & 4.63 & 4.31 & 3.87 & 2.76 \\
Big & 4.69 & 4.05 & 4.05 & 3.90 & 2.88 \\
\hline
\end{tabular}

\begin{tabular}{cccccc}
\hline Panel C. D/E ratio & \multicolumn{5}{c}{ Book-to-Market } \\
\cline { 2 - 6 } & Low & $\mathbf{2}$ & $\mathbf{3}$ & $\mathbf{4}$ & High \\
\hline Small & 3.52 & 1.27 & 1.23 & 1.43 & 3.88 \\
$\mathbf{2}$ & 0.69 & 0.78 & 0.97 & 1.33 & 2.61 \\
$\mathbf{3}$ & 0.45 & 0.67 & 0.86 & 1.30 & 2.66 \\
$\mathbf{4}$ & 0.42 & 0.66 & 0.91 & 1.23 & 2.59 \\
Big & 0.41 & 0.70 & 0.93 & 1.25 & 2.31 \\
\hline
\end{tabular}

\begin{tabular}{|c|c|c|c|c|c|}
\hline \multicolumn{6}{|c|}{ Panel D. Excess returns } \\
\hline & \multicolumn{5}{|c|}{ Book-to-Market } \\
\hline & Low & 2 & 3 & 4 & High \\
\hline Small & 1.20 & 0.99 & 0.97 & 1.14 & 0.92 \\
\hline 2 & 0.54 & 0.57 & 0.72 & 0.72 & 0.68 \\
\hline 3 & 0.48 & 0.51 & 0.75 & 0.88 & 1.22 \\
\hline 4 & 0.41 & 0.47 & 0.61 & 1.01 & 1.15 \\
\hline Big & 0.27 & 0.38 & 0.57 & 0.66 & 1.07 \\
\hline
\end{tabular}

25 size and B/M portfolios are formed as in Fama and French (1993) with rebalancing at the end of September each year from 1979 to 2005. Figures in panel A are the time series average of failure rates, in panel $\mathrm{B}$ are the time-series averages of z-scores, in panel $\mathrm{C}$ are the time-series averages of $\mathrm{D} / \mathrm{E}$ ratios and in panel $\mathrm{D}$ are the time-series averages of portfolio returns in excess of the risk-free rate for each of the 25 portfolios. 
Table 4: Time series regressions with market factor alone

\begin{tabular}{|c|c|c|c|c|c|c|c|c|c|c|}
\hline \multicolumn{11}{|c|}{$\mathrm{CAPM}: \mathbf{R}_{\mathrm{it}}-\mathbf{R}_{\mathrm{Ft}}=\beta_{1}+\beta_{\mathrm{RMRF}} \mathbf{R M R F}_{\mathrm{t}}+\varepsilon_{\mathrm{t}}$} \\
\hline & \multicolumn{10}{|c|}{ Book-to-market } \\
\hline & Low & 2 & 3 & 4 & High & Low & 2 & 3 & 4 & High \\
\hline & \multicolumn{5}{|c|}{$\beta_{1}$} & \multicolumn{5}{|c|}{$\mathbf{t}\left(\beta_{1}\right)$} \\
\hline Small & 1.00 & 0.90 & 0.66 & 0.85 & 0.67 & 1.95 & 2.30 & 2.06 & 3.29 & 2.54 \\
\hline 2 & 0.38 & 0.19 & 0.44 & 0.40 & 0.30 & 1.21 & 0.76 & 1.92 & 1.89 & 1.23 \\
\hline 3 & 0.08 & 0.14 & 0.41 & 0.52 & 0.83 & 0.31 & 0.70 & 2.10 & 2.40 & 3.04 \\
\hline 4 & -0.04 & 0.08 & 0.18 & 0.56 & 0.72 & -0.18 & 0.49 & 0.99 & 2.98 & 2.42 \\
\hline \multirow[t]{2}{*}{ Big } & -0.19 & -0.09 & 0.09 & 0.17 & 0.57 & -1.63 & -0.91 & 0.70 & 0.95 & 2.38 \\
\hline & \multicolumn{5}{|c|}{$\boldsymbol{\beta}_{\mathrm{RMRF}}$} & \multicolumn{5}{|c|}{$\mathbf{t}\left(\beta_{\mathrm{RMRF}}\right)$} \\
\hline Small & 0.86 & 0.86 & 0.65 & 0.63 & 0.72 & 7.58 & 9.92 & 9.13 & 10.93 & 12.18 \\
\hline 2 & 0.96 & 0.79 & 0.72 & 0.78 & 0.75 & 13.71 & 14.56 & 14.18 & 16.35 & 13.98 \\
\hline 3 & 0.89 & 0.81 & 0.77 & 0.79 & 0.88 & 15.95 & 18.02 & 17.78 & 16.33 & 14.44 \\
\hline 4 & 1.04 & 0.92 & 0.98 & 0.93 & 0.97 & 23.18 & 24.77 & 24.43 & 22.23 & 14.75 \\
\hline Big & 1.02 & 1.01 & 1.01 & 1.06 & 1.05 & 39.15 & 47.74 & 34.58 & 27.17 & 19.77 \\
\hline \multicolumn{6}{|c|}{ Adjusted R ${ }^{2}$} & & & & & \\
\hline Small & 0.15 & 0.23 & 0.20 & 0.27 & 0.31 & & & & & \\
\hline 2 & 0.37 & 0.40 & 0.38 & 0.45 & 0.38 & & & & & \\
\hline 3 & 0.44 & 0.50 & 0.49 & 0.45 & 0.39 & & & & & \\
\hline 4 & 0.62 & 0.66 & 0.65 & 0.60 & 0.40 & & & & & \\
\hline Big & 0.83 & 0.88 & 0.79 & 0.70 & 0.55 & & & & & \\
\hline
\end{tabular}

GRS F $=1.85(p-$ value $=0.009)$

25 size and B/M portfolios are formed as in Fama and French (1993) with rebalancing at the end of September each year from 1979 to 2005 . $R_{i}$ is the monthly value weighted return on portfolio $i$, and $R_{F}$ is the one-month T-bill rate at the beginning of the month. RMRF is the difference between monthly value weighted return on all stocks in the portfolios and $\mathrm{R}_{\mathrm{F}}$. Negative $\mathrm{B} / \mathrm{M}$ stocks are excluded. The last period return for failed stocks is set equal to $-100 \%$. 
Table 5: Fama-French three factor regressions

\begin{tabular}{|c|c|c|c|c|c|c|c|c|c|c|}
\hline & French & 93) $\mathbf{m}$ & I: $\mathbf{R}_{\mathrm{it}}-$ & $=\beta_{1}+$ & MRF RN & $2 \mathbf{F}_{t}+\beta_{S}$ & ${ }_{B} \mathrm{SMB}$ & $\beta_{\mathrm{HML}}$ & $\mathbf{M L}_{\mathrm{t}}+$ & \\
\hline & \multicolumn{10}{|c|}{ Book-to-market } \\
\hline & Low & 2 & 3 & 4 & High & Low & 2 & 3 & 4 & High \\
\hline & \multicolumn{5}{|c|}{$\beta_{1}$} & \multicolumn{5}{|c|}{$\mathbf{t}\left(\boldsymbol{\beta}_{1}\right)$} \\
\hline Small & 0.47 & 0.73 & 0.30 & 0.45 & 0.11 & 1.11 & 2.39 & 1.24 & 2.50 & 0.63 \\
\hline 2 & 0.14 & -0.14 & 0.09 & -0.07 & -0.32 & 0.70 & -0.95 & 0.66 & -0.64 & -2.64 \\
\hline 3 & -0.12 & -0.14 & 0.00 & 0.03 & 0.12 & -0.80 & -1.41 & 0.04 & 0.25 & 0.72 \\
\hline 4 & -0.13 & -0.21 & -0.19 & 0.17 & 0.11 & -0.99 & -1.76 & -1.38 & 1.16 & 0.46 \\
\hline \multirow[t]{2}{*}{ Big } & 0.06 & -0.07 & -0.02 & -0.05 & 0.18 & 0.63 & -0.73 & -0.19 & -0.31 & 0.93 \\
\hline & \multicolumn{5}{|c|}{$\beta_{\text {RMRF }}$} & \multicolumn{5}{|c|}{$\mathbf{t}\left(\boldsymbol{\beta}_{\mathrm{RMRF}}\right)$} \\
\hline Small & 1.17 & 1.05 & 0.87 & 0.83 & 0.96 & 12.16 & 15.13 & 15.95 & 20.46 & 25.19 \\
\hline 2 & 1.17 & 0.99 & 0.91 & 0.98 & 1.00 & 25.37 & 28.82 & 30.98 & 39.24 & 35.84 \\
\hline 3 & 1.07 & 0.98 & 0.95 & 0.99 & 1.13 & 32.27 & 43.52 & 38.94 & 32.35 & 29.25 \\
\hline 4 & 1.15 & 1.05 & 1.13 & 1.07 & 1.18 & 39.89 & 39.19 & 36.08 & 31.51 & 21.71 \\
\hline \multirow[t]{2}{*}{ Big } & 0.97 & 1.00 & 1.02 & 1.09 & 1.11 & 46.95 & 45.50 & 36.44 & 30.49 & 25.21 \\
\hline & \multicolumn{5}{|c|}{$\boldsymbol{\beta}_{\mathrm{SMB}}$} & \multicolumn{5}{|c|}{$\mathbf{t}\left(\boldsymbol{\beta}_{\text {SMB }}\right)$} \\
\hline Small & 1.47 & 1.06 & 1.06 & 0.94 & 1.01 & 12.81 & 12.88 & 16.26 & 19.35 & 22.39 \\
\hline 2 & 1.10 & 0.94 & 0.92 & 0.90 & 0.99 & 20.02 & 23.12 & 26.33 & 30.21 & 30.03 \\
\hline 3 & 0.92 & 0.85 & 0.80 & 0.83 & 0.94 & 23.49 & 31.59 & 27.65 & 22.84 & 20.50 \\
\hline 4 & 0.66 & 0.59 & 0.57 & 0.51 & 0.76 & 19.23 & 18.54 & 15.24 & 12.77 & 11.76 \\
\hline \multirow[t]{2}{*}{ Big } & -0.14 & -0.03 & -0.04 & -0.01 & 0.02 & -5.51 & -1.07 & -1.22 & -0.25 & 0.43 \\
\hline & \multicolumn{5}{|c|}{$\beta_{\text {HML }}$} & \multicolumn{5}{|c|}{$\mathbf{t}\left(\boldsymbol{\beta}_{\mathrm{HML}}\right)$} \\
\hline Small & 0.16 & -0.35 & 0.08 & 0.24 & 0.54 & 1.21 & -3.59 & 1.01 & 4.31 & 10.26 \\
\hline 2 & -0.22 & 0.08 & 0.14 & 0.42 & 0.67 & -3.37 & 1.67 & 3.44 & 12.01 & 17.34 \\
\hline 3 & -0.20 & 0.04 & 0.33 & 0.50 & 0.90 & -4.32 & 1.33 & 9.81 & 11.68 & 16.73 \\
\hline 4 & -0.25 & 0.23 & 0.41 & 0.49 & 0.80 & -6.14 & 6.13 & 9.53 & 10.43 & 10.58 \\
\hline Big & -0.44 & -0.02 & 0.28 & 0.47 & 0.82 & -15.47 & -0.50 & 7.04 & 9.41 & 13.37 \\
\hline \multicolumn{6}{|c|}{ Adjusted $R^{2}$} & & & & & \\
\hline Small & 0.44 & 0.54 & 0.57 & 0.66 & 0.74 & & & & & \\
\hline 2 & 0.75 & 0.78 & 0.81 & 0.86 & 0.85 & & & & & \\
\hline 3 & 0.82 & 0.88 & 0.85 & 0.80 & 0.78 & & & & & \\
\hline 4 & 0.86 & 0.83 & 0.81 & 0.76 & 0.63 & & & & & \\
\hline Big & 0.90 & 0.88 & 0.82 & 0.77 & 0.71 & & & & & \\
\hline
\end{tabular}

GRS F $=1.21(p-$ value $=0.227)$

25 size and B/M portfolios are formed as in Fama and French (1993) with rebalancing at the end of September each year from 1979 to 2005 . $R_{i}$ is the monthly value weighted return on portfolio $i$, and $R_{F}$ is the one-month T-bill rate at the beginning of the month. RMRF is the difference between monthly value weighted return on all stocks in the portfolios and $\mathrm{R}_{\mathrm{F}}$. SMB is the return on the mimicking portfolio for the size factor and HML is the return on the mimicking portfolio for the $\mathrm{B} / \mathrm{M}$ factor in stock returns. Negative B/M stocks are excluded. The last period return for failed stocks is set equal to $-100 \%$. 
Table 6: Ferguson-Shockley three factor regressions

\begin{tabular}{|c|c|c|c|c|c|c|c|c|c|c|}
\hline \multicolumn{11}{|c|}{ Fama and Shockley $(2003) \mathrm{m}$} \\
\hline & \multicolumn{10}{|c|}{ Book-to-market } \\
\hline & Low & 2 & 3 & 4 & High & Low & 2 & 3 & 4 & High \\
\hline & \multicolumn{5}{|c|}{$\beta_{1}$} & \multicolumn{5}{|c|}{$\mathbf{t}\left(\beta_{1}\right)$} \\
\hline Small & 1.57 & 1.39 & 0.93 & 0.88 & 0.70 & 3.39 & 3.90 & 3.17 & 3.84 & 3.17 \\
\hline 2 & 0.84 & 0.35 & 0.58 & 0.43 & 0.21 & 3.00 & 1.54 & 2.83 & 2.34 & 1.09 \\
\hline 3 & 0.44 & 0.31 & 0.44 & 0.43 & 0.70 & 1.92 & 1.64 & 2.50 & 2.21 & 2.96 \\
\hline 4 & 0.26 & 0.05 & 0.05 & 0.41 & 0.50 & 1.41 & 0.31 & 0.30 & 2.39 & 1.86 \\
\hline \multirow[t]{2}{*}{ Big } & -0.10 & -0.14 & -0.05 & 0.08 & 0.55 & -0.87 & -1.48 & -0.42 & 0.47 & 2.28 \\
\hline & \multicolumn{5}{|c|}{$\beta_{\text {RMRF }}$} & \multicolumn{5}{|c|}{$\mathbf{t}\left(\boldsymbol{\beta}_{\mathrm{RMRF}}\right)$} \\
\hline Small & 0.63 & 0.69 & 0.52 & 0.54 & 0.62 & 6.08 & 8.62 & 7.88 & 10.52 & 12.41 \\
\hline 2 & 0.81 & 0.70 & 0.62 & 0.70 & 0.68 & 12.87 & 13.64 & 13.58 & 16.82 & 15.38 \\
\hline 3 & 0.78 & 0.73 & 0.70 & 0.74 & 0.82 & 15.22 & 17.29 & 17.77 & 17.17 & 15.48 \\
\hline 4 & 0.96 & 0.89 & 0.97 & 0.91 & 0.94 & 22.98 & 24.77 & 25.42 & 23.60 & 15.48 \\
\hline \multirow[t]{2}{*}{ Big } & 1.02 & 1.02 & 1.03 & 1.07 & 1.04 & 40.14 & 47.49 & 36.08 & 26.81 & 19.01 \\
\hline & \multicolumn{5}{|c|}{$\beta_{\mathrm{NMP}}$} & \multicolumn{5}{|c|}{$\mathbf{t}\left(\beta_{\mathrm{NMP}}\right)$} \\
\hline Small & 2.18 & 1.50 & 1.34 & 1.11 & 1.31 & 9.30 & 8.30 & 8.98 & 9.59 & 11.71 \\
\hline 2 & 1.30 & 0.89 & 1.00 & 0.97 & 1.12 & 9.19 & 7.62 & 9.62 & 10.39 & 11.28 \\
\hline 3 & 0.90 & 0.75 & 0.77 & 0.77 & 1.06 & 7.71 & 7.91 & 8.60 & 7.89 & 8.89 \\
\hline 4 & 0.58 & 0.45 & 0.39 & 0.45 & 0.78 & 6.15 & 5.49 & 4.50 & 5.13 & 5.73 \\
\hline \multirow[t]{2}{*}{ Big } & -0.14 & -0.09 & -0.03 & 0.08 & 0.24 & -2.38 & -1.88 & -0.50 & 0.83 & 1.97 \\
\hline & \multicolumn{5}{|c|}{$\beta_{\text {DE }}$} & \multicolumn{5}{|c|}{$\mathbf{t}\left(\boldsymbol{\beta}_{\mathrm{DE}}\right)$} \\
\hline Small & 0.45 & 0.17 & 0.39 & 0.61 & 0.74 & 3.13 & 1.50 & 4.26 & 8.59 & 10.61 \\
\hline 2 & 0.10 & 0.28 & 0.38 & 0.53 & 0.79 & 1.12 & 3.86 & 5.93 & 9.20 & 12.80 \\
\hline 3 & 0.00 & 0.20 & 0.41 & 0.60 & 0.83 & -0.06 & 3.42 & 7.32 & 9.90 & 11.22 \\
\hline 4 & -0.10 & 0.31 & 0.42 & 0.48 & 0.78 & -1.66 & 6.19 & 7.81 & 8.91 & 9.16 \\
\hline Big & -0.22 & 0.03 & 0.20 & 0.17 & 0.17 & -6.13 & 0.93 & 4.91 & 2.99 & 2.19 \\
\hline \multicolumn{11}{|c|}{ Adjusted R ${ }^{2}$} \\
\hline Small & 0.33 & 0.38 & 0.36 & 0.45 & 0.54 & & & & & \\
\hline 2 & 0.52 & 0.49 & 0.52 & 0.61 & 0.61 & & & & & \\
\hline 3 & 0.55 & 0.58 & 0.60 & 0.59 & 0.57 & & & & & \\
\hline 4 & 0.69 & 0.70 & 0.70 & 0.68 & 0.52 & & & & & \\
\hline Big & 0.84 & 0.88 & 0.81 & 0.70 & 0.55 & & & & & \\
\hline
\end{tabular}

GRS F $=2.29(p-$ value $=0.001)$

Twenty-five size and B/M portfolios are formed as in Fama and French (1993) with rebalancing at the end of September each year from 1979 to 2005 . $R_{i}$ is the monthly equally weighted return on portfolio $i$, and $R_{F}$ is the one-month $T$-bill rate at the beginning of the month. RMRF is the difference between monthly value weighted return on all stocks in the portfolios and $\mathrm{R}_{\mathrm{F}}$. NMP is the return on the mimicking portfolio for $\mathrm{z}$-score factor and DE is the return on the mimicking portfolio for leverage factor in stock returns. Negative B/M stocks are excluded. The last period return for failed stocks is set equal to $-100 \%$. 
Table 7: Five factor regressions

\begin{tabular}{|c|c|c|c|c|c|c|c|c|c|c|}
\hline \multicolumn{11}{|c|}{ 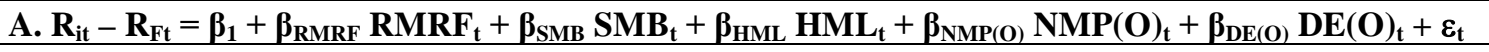 } \\
\hline & \multicolumn{10}{|c|}{ Book-to-Market } \\
\hline & Low & 2 & 3 & 4 & High & Low & 2 & 3 & 4 & High \\
\hline & \multicolumn{5}{|c|}{$\beta_{1}$} & \multicolumn{5}{|c|}{$\mathbf{t}\left(\boldsymbol{\beta}_{1}\right)$} \\
\hline Small & 0.89 & 0.99 & 0.44 & 0.45 & 0.18 & 2.12 & 3.25 & 1.80 & 2.55 & 1.08 \\
\hline 2 & 0.31 & -0.17 & 0.10 & -0.08 & -0.35 & 1.57 & -1.10 & 0.78 & -0.72 & -2.93 \\
\hline 3 & -0.06 & -0.18 & -0.04 & -0.08 & 0.09 & -0.43 & -1.76 & -0.39 & -0.57 & 0.50 \\
\hline 4 & -0.10 & -0.32 & -0.34 & 0.07 & 0.01 & -0.82 & -2.72 & -2.52 & 0.45 & 0.04 \\
\hline \multirow[t]{2}{*}{ Big } & 0.07 & -0.12 & -0.06 & -0.01 & 0.33 & 0.81 & -1.24 & -0.50 & -0.07 & 1.80 \\
\hline & \multicolumn{5}{|c|}{$\beta_{\text {RMRF }}$} & \multicolumn{5}{|c|}{$\mathbf{t}\left(\boldsymbol{\beta}_{\mathrm{RMRF}}\right)$} \\
\hline Small & 1.02 & 0.95 & 0.81 & 0.79 & 0.90 & 9.97 & 12.64 & 13.62 & 18.23 & 22.00 \\
\hline 2 & 1.13 & 1.01 & 0.90 & 0.98 & 0.98 & 23.12 & 26.84 & 27.79 & 35.60 & 33.33 \\
\hline 3 & 1.08 & 1.01 & 0.97 & 1.02 & 1.13 & 31.52 & 41.66 & 36.34 & 31.26 & 26.69 \\
\hline 4 & 1.18 & 1.10 & 1.18 & 1.09 & 1.19 & 39.30 & 38.11 & 35.79 & 30.05 & 20.21 \\
\hline \multirow[t]{2}{*}{ Big } & 0.95 & 1.01 & 1.02 & 1.09 & 1.10 & 42.19 & 42.40 & 33.54 & 27.80 & 24.40 \\
\hline & \multicolumn{5}{|c|}{$\beta_{\text {SMB }}$} & \multicolumn{5}{|c|}{$\mathbf{t}\left(\boldsymbol{\beta}_{\mathrm{SMB}}\right)$} \\
\hline Small & 1.42 & 1.03 & 1.04 & 0.92 & 1.00 & 12.71 & 12.65 & 15.98 & 19.53 & 22.30 \\
\hline 2 & 1.09 & 0.95 & 0.92 & 0.90 & 0.99 & 20.40 & 23.15 & 25.98 & 29.98 & 30.79 \\
\hline 3 & 0.93 & 0.85 & 0.81 & 0.84 & 0.94 & 24.81 & 32.35 & 27.76 & 23.68 & 20.44 \\
\hline 4 & 0.67 & 0.61 & 0.58 & 0.52 & 0.76 & 20.47 & 19.33 & 16.22 & 13.18 & 11.89 \\
\hline \multirow[t]{2}{*}{ Big } & -0.14 & -0.02 & -0.04 & -0.01 & 0.02 & -5.70 & -0.94 & -1.21 & -0.26 & 0.39 \\
\hline & \multicolumn{5}{|c|}{$\beta_{\mathrm{HML}}$} & \multicolumn{5}{|c|}{$\mathbf{t}\left(\boldsymbol{\beta}_{\mathrm{HML}}\right)$} \\
\hline Small & 0.13 & -0.37 & 0.06 & 0.24 & 0.53 & 1.00 & -3.90 & 0.84 & 4.27 & 10.22 \\
\hline 2 & -0.23 & 0.08 & 0.14 & 0.42 & 0.67 & -3.63 & 1.76 & 3.37 & 11.97 & 17.86 \\
\hline 3 & -0.20 & 0.05 & 0.34 & 0.50 & 0.90 & -4.48 & 1.57 & 9.96 & 12.19 & 16.76 \\
\hline 4 & -0.24 & 0.24 & 0.43 & 0.50 & 0.80 & -6.34 & 6.53 & 10.17 & 10.76 & 10.72 \\
\hline \multirow[t]{2}{*}{ Big } & -0.45 & -0.01 & 0.28 & 0.47 & 0.82 & -15.63 & -0.43 & 7.10 & 9.41 & 14.29 \\
\hline & \multicolumn{5}{|c|}{$\beta_{\mathrm{NMP}(0)}$} & \multicolumn{5}{|c|}{$\mathbf{t}\left(\boldsymbol{\beta}_{\mathrm{NMP}(0)}\right)$} \\
\hline Small & 0.88 & 0.63 & 0.36 & 0.27 & 0.36 & 3.41 & 3.37 & 2.40 & 2.45 & 3.48 \\
\hline 2 & 0.23 & -0.13 & 0.07 & 0.02 & 0.10 & 1.90 & -1.42 & 0.84 & 0.35 & 1.37 \\
\hline 3 & -0.11 & -0.19 & -0.13 & -0.15 & 0.02 & -1.33 & -3.13 & -1.90 & -1.81 & 0.19 \\
\hline 4 & -0.17 & -0.25 & -0.31 & -0.15 & -0.06 & -2.23 & -3.47 & -3.79 & -1.67 & -0.40 \\
\hline \multirow[t]{2}{*}{ Big } & 0.10 & -0.06 & 0.00 & 0.01 & 0.04 & 1.75 & -1.05 & -0.03 & 0.06 & 0.37 \\
\hline & \multicolumn{5}{|c|}{$\beta_{\mathrm{DE}(\mathbf{O})}$} & \multicolumn{5}{|c|}{$\mathbf{t}\left(\boldsymbol{\beta}_{\mathrm{DE}(\mathbf{O})}\right)$} \\
\hline Small & -0.08 & 0.44 & 0.61 & 4.66 & 3.78 & -0.45 & 0.44 & 0.61 & 4.66 & 3.78 \\
\hline 2 & -0.20 & -0.10 & 0.04 & 0.06 & 0.23 & -2.53 & -1.62 & 0.68 & 1.42 & 4.71 \\
\hline 3 & -0.32 & -0.15 & -0.03 & 0.13 & 0.13 & -5.62 & -3.72 & -0.71 & 2.40 & 1.87 \\
\hline 4 & -0.30 & 0.00 & 0.03 & 0.11 & 0.21 & -6.06 & -0.08 & 0.51 & 1.79 & 2.20 \\
\hline Big & 0.08 & 0.07 & 0.11 & -0.10 & -0.39 & 2.15 & 1.67 & 2.25 & -1.57 & -5.29 \\
\hline \multicolumn{6}{|c|}{ Adjusted $\mathbf{R}^{2}$} & & & & & \\
\hline Small & 0.48 & 0.56 & 0.58 & 0.68 & 0.75 & & & & & \\
\hline 2 & 0.77 & 0.78 & 0.81 & 0.86 & 0.86 & & & & & \\
\hline 3 & 0.84 & 0.89 & 0.85 & 0.81 & 0.78 & & & & & \\
\hline 4 & 0.87 & 0.84 & 0.82 & 0.77 & 0.64 & & & & & \\
\hline Big & 0.90 & 0.88 & 0.82 & 0.77 & 0.75 & & & & & \\
\hline
\end{tabular}

GRS F $=1.78(p-$ value $=0.015)$ 


\begin{tabular}{|c|c|c|c|c|c|c|c|c|c|c|}
\hline \multirow{2}{*}{\multicolumn{11}{|c|}{$\begin{array}{c}\text { B. } \mathbf{R}_{\mathrm{it}}-\mathbf{R}_{\mathrm{Ft}}=\beta_{1}+\beta_{\mathrm{RMRF}} \mathrm{RMRF}_{\mathrm{t}}+\beta_{\mathrm{SMB}(0)} \operatorname{SMB}(\mathbf{O})_{\mathrm{t}}+\beta_{\mathrm{HML}(0)} \mathrm{HML}(\mathbf{O})_{\mathrm{t}}+\beta_{\mathrm{NMP}} \mathrm{NMP}_{\mathrm{t}}+\beta_{\mathrm{DE}} \mathrm{DE}_{\mathrm{t}}+\varepsilon_{\mathrm{t}} \\
\text { Book-to-Market }\end{array}$}} \\
\hline & & & & & & & & & & \\
\hline & \multirow{2}{*}{\multicolumn{5}{|c|}{$\bar{\beta}_{1}$}} & Low & 2 & 3 & 4 & High \\
\hline & & & & & & \multicolumn{5}{|c|}{$t\left(\beta_{1}\right)$} \\
\hline Small & 0.89 & 0.99 & 0.44 & 0.45 & 0.18 & 2.12 & 3.25 & 1.80 & 2.55 & 1.08 \\
\hline 2 & 0.31 & -0.17 & 0.10 & -0.08 & -0.35 & 1.57 & -1.09 & 0.79 & -0.72 & -2.93 \\
\hline 3 & -0.06 & -0.17 & -0.04 & -0.08 & 0.09 & -0.42 & -1.75 & -0.39 & -0.57 & 0.51 \\
\hline 4 & -0.10 & -0.32 & -0.34 & 0.07 & 0.01 & -0.82 & -2.71 & -2.51 & 0.45 & 0.04 \\
\hline \multirow[t]{2}{*}{ Big } & 0.07 & -0.12 & -0.06 & -0.01 & 0.33 & 0.81 & -1.23 & -0.50 & -0.07 & 1.79 \\
\hline & \multicolumn{5}{|c|}{$\boldsymbol{\beta}_{\text {RMRF }}$} & \multicolumn{5}{|c|}{$\mathbf{t}\left(\boldsymbol{\beta}_{\mathrm{RMRF}}\right)$} \\
\hline Small & 1.02 & 0.95 & 0.81 & 0.79 & 0.90 & 9.97 & 12.64 & 13.61 & 18.22 & 22.00 \\
\hline 2 & 1.13 & 1.01 & 0.90 & 0.98 & 0.98 & 23.11 & 26.83 & 27.78 & 35.59 & 33.32 \\
\hline 3 & 1.08 & 1.01 & 0.97 & 1.02 & 1.13 & 31.52 & 41.65 & 36.33 & 31.25 & 26.69 \\
\hline 4 & 1.18 & 1.10 & 1.18 & 1.09 & 1.19 & 39.30 & 38.10 & 35.78 & 30.04 & 20.21 \\
\hline \multirow[t]{2}{*}{ Big } & 0.95 & 1.01 & 1.02 & 1.09 & 1.10 & 42.19 & 42.40 & 33.54 & 27.79 & 24.39 \\
\hline & \multicolumn{5}{|c|}{$\beta_{\mathrm{SMB}(0)}$} & \multicolumn{5}{|c|}{$\mathbf{t}\left(\boldsymbol{\beta}_{\mathrm{SMB}(0)}\right)$} \\
\hline Small & 1.25 & 0.90 & 0.96 & 0.82 & 0.89 & 9.10 & 8.92 & 11.96 & 14.16 & 16.17 \\
\hline 2 & 1.07 & 0.99 & 0.90 & 0.89 & 0.94 & 16.25 & 19.59 & 20.66 & 23.97 & 23.70 \\
\hline 3 & 1.00 & 0.91 & 0.84 & 0.85 & 0.92 & 21.55 & 28.05 & 23.36 & 19.51 & 16.21 \\
\hline 4 & 0.74 & 0.66 & 0.64 & 0.54 & 0.74 & 18.45 & 17.01 & 14.51 & 11.03 & 9.44 \\
\hline \multirow[t]{2}{*}{ Big } & -0.17 & -0.02 & -0.06 & 0.00 & 0.06 & -5.64 & -0.64 & -1.33 & 0.02 & 1.04 \\
\hline & \multicolumn{5}{|c|}{$\beta_{\mathrm{HML}(0)}$} & \multicolumn{5}{|c|}{$\mathbf{t}\left(\boldsymbol{\beta}_{\mathrm{HML}(0)}\right)$} \\
\hline Small & 0.27 & -0.34 & 0.06 & 0.05 & 0.41 & 1.68 & -2.85 & 0.68 & 0.73 & 6.27 \\
\hline 2 & -0.07 & 0.13 & 0.12 & 0.38 & 0.53 & -0.91 & 2.26 & 2.39 & 8.72 & 11.42 \\
\hline 3 & 0.00 & 0.12 & 0.35 & 0.41 & 0.82 & -0.08 & 3.21 & 8.14 & 7.87 & 12.23 \\
\hline 4 & -0.07 & 0.21 & 0.37 & 0.41 & 0.66 & -1.42 & 4.70 & 7.18 & 7.17 & 7.07 \\
\hline \multirow[t]{2}{*}{ Big } & -0.49 & -0.06 & 0.20 & 0.53 & 1.07 & -13.60 & -1.63 & 4.20 & 8.61 & 15.04 \\
\hline & \multicolumn{5}{|c|}{$\boldsymbol{\beta}_{\mathrm{NMP}}$} & \multicolumn{5}{|c|}{$\mathbf{t}\left(\boldsymbol{\beta}_{\mathrm{NMP}}\right)$} \\
\hline Small & 1.99 & 1.37 & 1.19 & 0.99 & 1.17 & 9.50 & 8.97 & 9.80 & 11.12 & 13.99 \\
\hline 2 & 1.15 & 0.74 & 0.86 & 0.83 & 0.97 & 11.50 & 9.61 & 12.99 & 14.80 & 16.13 \\
\hline 3 & 0.75 & 0.61 & 0.64 & 0.64 & 0.91 & 10.64 & 12.40 & 11.66 & 9.55 & 10.48 \\
\hline 4 & 0.47 & 0.34 & 0.28 & 0.36 & 0.66 & 7.65 & 5.83 & 4.22 & 4.84 & 5.48 \\
\hline \multirow[t]{2}{*}{ Big } & -0.10 & -0.09 & -0.03 & 0.06 & 0.21 & -2.20 & -1.78 & -0.45 & 0.80 & 2.30 \\
\hline & \multicolumn{5}{|c|}{$\beta_{\mathrm{DE}}$} & \multicolumn{5}{|c|}{$\mathbf{t}\left(\boldsymbol{\beta}_{\mathrm{DE}}\right)$} \\
\hline Small & 0.43 & 1.62 & 5.02 & 11.01 & 13.97 & 3.36 & 1.62 & 5.02 & 11.01 & 13.97 \\
\hline 2 & 0.08 & 0.26 & 0.37 & 0.52 & 0.77 & 1.31 & 5.53 & 8.95 & 14.91 & 20.79 \\
\hline 3 & -0.02 & 0.19 & 0.39 & 0.58 & 0.81 & -0.49 & 6.09 & 11.60 & 14.24 & 15.24 \\
\hline 4 & -0.11 & 0.30 & 0.40 & 0.47 & 0.76 & -2.90 & 8.25 & 9.77 & 10.31 & 10.28 \\
\hline Big & -0.21 & 0.03 & 0.20 & 0.17 & 0.16 & -7.55 & 0.94 & 5.12 & 3.35 & 2.88 \\
\hline \multicolumn{6}{|c|}{ Adjusted $R^{2}$} & & & & & \\
\hline Small & 0.48 & 0.56 & 0.58 & 0.68 & 0.75 & & & & & \\
\hline 2 & 0.77 & 0.78 & 0.81 & 0.86 & 0.86 & & & & & \\
\hline 3 & 0.84 & 0.89 & 0.85 & 0.81 & 0.78 & & & & & \\
\hline 4 & 0.87 & 0.84 & 0.82 & 0.77 & 0.64 & & & & & \\
\hline Big & 0.90 & 0.88 & 0.82 & 0.77 & 0.75 & & & & & \\
\hline
\end{tabular}

Twenty-five size and B/M portfolios are formed as in Fama and French (1993) with rebalancing at the end of September each year from 1979 to 2005 . $R_{i}$ is the monthly equally weighted return on portfolio $i$, and $R_{F}$ is the one-month $T$-bill rate at the beginning of the month. RMRF is the difference between monthly value weighted return on all stocks in the portfolios and $\mathrm{R}_{\mathrm{F}} \mathrm{SMB}$ is the return on the mimicking portfolio for the size factor, HML is the return on the mimicking portfolio for the $\mathrm{B} / \mathrm{M}$ 
factor, NMP is the return on the mimicking portfolio for the z-score factor and DE is the return on the mimicking portfolio for the leverage factor in stock returns. Negative $B / M$ stocks are excluded. The last period return for failed stocks is set equal to $-100 \%$. 
Table 8: Summary statistics of different models

\begin{tabular}{lcccccc}
\hline & $\bar{\alpha}(\%)$ & $|\bar{\alpha}|(\%)$ & $\operatorname{RMSE}(\%)$ & $\operatorname{Min}(\%)$ & $\operatorname{Max}(\%)$ & Average $^{2}$ \\
\hline CAPM & 0.39 & 0.42 & 0.51 & -0.19 & 1.00 & 0.48 \\
FF three-factor & 0.06 & 0.18 & 0.24 & -0.32 & 0.73 & 0.76 \\
FS three-factor & 0.47 & 0.50 & 0.63 & -0.14 & 1.57 & 0.59 \\
Five factor & 0.08 & 0.23 & 0.34 & -0.35 & 0.99 & 0.77 \\
\hline
\end{tabular}

The table presents the average pricing error $(\bar{\alpha})$, average absolute pricing error $(|\bar{\alpha}|)$, root mean squared pricing error (RMSE), minimum and maximum pricing errors and average adjusted $R^{2}$. CAPM refers to the single factor regressions in table 4 , FF threefactor refers to the regressions in table 5, FS three-factor refers to the regressions in table 6, and Five factor refers to the regressions in table 7. 
Table 6A: Ferguson-Shockley three factor regressions

\begin{tabular}{|c|c|c|c|c|c|c|c|c|c|c|}
\hline \multicolumn{11}{|c|}{ Fama and Shockley (2003) model: $R_{i t}-R_{F t}=\beta_{1}+\beta_{R M R F} R_{M R F}+\beta_{N M P} N_{t} P_{t}+\beta_{D E} D_{t}+\varepsilon_{t}$} \\
\hline & \multicolumn{10}{|c|}{ Book-to-market } \\
\hline & Low & 2 & 3 & 4 & High & Low & 2 & 3 & 4 & High \\
\hline & \multicolumn{5}{|c|}{$\beta_{1}$} & \multicolumn{5}{|c|}{$\mathbf{t}\left(\boldsymbol{\beta}_{1}\right)$} \\
\hline Small & 1.63 & 1.66 & 1.11 & 0.93 & 0.69 & 3.39 & 4.71 & 3.80 & 4.05 & 3.15 \\
\hline 2 & 1.09 & 0.51 & 0.65 & 0.44 & 0.14 & 3.96 & 2.22 & 3.16 & 2.37 & 0.75 \\
\hline 3 & 0.64 & 0.42 & 0.44 & 0.35 & 0.56 & 2.85 & 2.25 & 2.43 & 1.82 & 2.42 \\
\hline 4 & 0.47 & 0.05 & -0.03 & 0.30 & 0.30 & 2.65 & 0.29 & -0.18 & 1.74 & 1.14 \\
\hline \multirow[t]{2}{*}{ Big } & -0.02 & -0.19 & -0.19 & 0.00 & 0.52 & -0.18 & -1.97 & -1.55 & 0.02 & 2.11 \\
\hline & \multicolumn{5}{|c|}{$\beta_{\text {RMRF }}$} & \multicolumn{5}{|c|}{$\mathbf{t}\left(\boldsymbol{\beta}_{\text {RMRF }}\right)$} \\
\hline Small & 0.62 & 0.64 & 0.48 & 0.52 & 0.60 & 5.86 & 8.19 & 7.48 & 10.25 & 12.43 \\
\hline 2 & 0.77 & 0.67 & 0.61 & 0.69 & 0.67 & 12.54 & 13.32 & 13.29 & 16.66 & 15.68 \\
\hline 3 & 0.75 & 0.71 & 0.70 & 0.75 & 0.83 & 14.95 & 17.04 & 17.62 & 17.41 & 15.99 \\
\hline 4 & 0.92 & 0.88 & 0.98 & 0.92 & 0.96 & 23.30 & 24.53 & 25.71 & 24.26 & 16.14 \\
\hline \multirow[t]{2}{*}{ Big } & 1.01 & 1.03 & 1.05 & 1.08 & 1.04 & 40.20 & 47.90 & 38.25 & 27.06 & 18.92 \\
\hline & \multicolumn{5}{|c|}{$\beta_{\text {NMP }}$} & \multicolumn{5}{|c|}{$t\left(\beta_{\mathrm{NMP}}\right)$} \\
\hline Small & 2.19 & 1.94 & 1.54 & 1.00 & 1.09 & 8.41 & 10.12 & 9.74 & 8.10 & 9.19 \\
\hline 2 & 1.73 & 1.07 & 1.01 & 0.82 & 0.77 & 11.61 & 8.69 & 9.06 & 8.14 & 7.36 \\
\hline 3 & 1.28 & 0.90 & 0.63 & 0.47 & 0.59 & 10.51 & 8.89 & 6.55 & 4.48 & 4.72 \\
\hline 4 & 1.00 & 0.34 & 0.12 & 0.11 & 0.22 & 10.32 & 3.89 & 1.32 & 1.18 & 1.49 \\
\hline \multirow[t]{2}{*}{ Big } & 0.06 & -0.18 & -0.34 & -0.11 & 0.12 & 1.05 & -3.47 & -5.00 & -1.12 & 0.87 \\
\hline & \multicolumn{5}{|c|}{$\boldsymbol{\beta}_{\text {DE }}$} & \multicolumn{5}{|c|}{$\mathbf{t}\left(\boldsymbol{\beta}_{\mathrm{DE}}\right)$} \\
\hline Small & -0.22 & -0.61 & -0.17 & 0.30 & 0.46 & -1.21 & -4.53 & -1.52 & 3.50 & 5.50 \\
\hline 2 & -0.59 & -0.13 & 0.04 & 0.30 & 0.64 & -5.64 & -1.56 & 0.53 & 4.22 & 8.74 \\
\hline 3 & -0.51 & -0.13 & 0.23 & 0.54 & 0.79 & -5.95 & -1.85 & 3.43 & 7.41 & 8.94 \\
\hline 4 & -0.53 & 0.22 & 0.46 & 0.55 & 0.89 & -7.88 & 3.59 & 7.06 & 8.52 & 8.78 \\
\hline Big & -0.30 & 0.12 & 0.40 & 0.27 & 0.14 & -7.00 & 3.22 & 8.43 & 3.92 & 1.53 \\
\hline \multicolumn{6}{|c|}{ Adjusted $\mathbf{R}^{2}$} & & & & & \\
\hline Small & 0.31 & 0.41 & 0.39 & 0.47 & 0.57 & & & & & \\
\hline 2 & 0.55 & 0.51 & 0.53 & 0.61 & 0.63 & & & & & \\
\hline 3 & 0.58 & 0.60 & 0.60 & 0.60 & 0.60 & & & & & \\
\hline 4 & 0.73 & 0.70 & 0.71 & 0.70 & 0.55 & & & & & \\
\hline Big & 0.85 & 0.88 & 0.83 & 0.71 & 0.55 & & & & & \\
\hline
\end{tabular}

The table differs from table 6 in that NMP and DE are formed by single sorts. 
Table 7A: Five factor regressions

\begin{tabular}{|c|c|c|c|c|c|c|c|c|c|c|}
\hline \multicolumn{11}{|c|}{ A. $R_{i t}-R_{\mathrm{Ft}}=\beta_{1}+\beta_{\mathrm{RMRF}} \mathrm{RMRF}_{\mathrm{t}}+\beta_{\mathrm{SMB}} \mathrm{SMB}_{\mathrm{t}}+\beta_{\mathrm{HML}} \mathrm{HML}_{\mathrm{t}}+\beta_{\mathrm{NMP}(0)} \mathrm{NMP}(\mathrm{O})_{\mathrm{t}}+\beta_{\mathrm{DE}(0)} \mathrm{DE}(\mathrm{O})_{\mathrm{t}}+\varepsilon_{\mathrm{t}}$} \\
\hline & \multicolumn{10}{|c|}{ Book-to-Market } \\
\hline & Low & 2 & 3 & 4 & High & Low & 2 & 3 & 4 & High \\
\hline & \multicolumn{5}{|c|}{$\beta_{1}$} & \multicolumn{5}{|c|}{$\mathbf{t}\left(\boldsymbol{\beta}_{1}\right)$} \\
\hline Small & 0.85 & 1.11 & 0.54 & 0.43 & 0.17 & 1.94 & 3.57 & 2.18 & 2.39 & 1.03 \\
\hline 2 & 0.43 & -0.09 & 0.10 & -0.09 & -0.40 & 2.17 & -0.60 & 0.74 & -0.81 & -3.32 \\
\hline 3 & 0.03 & -0.14 & -0.08 & -0.16 & 0.03 & 0.23 & -1.38 & -0.69 & -1.18 & 0.19 \\
\hline 4 & 0.02 & -0.35 & -0.42 & -0.02 & -0.13 & 0.14 & -2.95 & -3.06 & -0.13 & -0.55 \\
\hline \multirow[t]{2}{*}{ Big } & 0.07 & -0.18 & -0.16 & 0.02 & 0.51 & 0.75 & -1.87 & -1.27 & 0.14 & 2.88 \\
\hline & \multicolumn{5}{|c|}{$\beta_{\text {RMRF }}$} & \multicolumn{5}{|c|}{$\mathbf{t}\left(\boldsymbol{\beta}_{\mathrm{RMRF}}\right)$} \\
\hline Small & 1.05 & 0.93 & 0.79 & 0.78 & 0.89 & 9.83 & 12.30 & 13.17 & 17.72 & 21.52 \\
\hline 2 & 1.12 & 1.00 & 0.90 & 0.98 & 0.98 & 22.85 & 26.36 & 27.40 & 35.07 & 33.06 \\
\hline 3 & 1.08 & 1.01 & 0.98 & 1.03 & 1.13 & 31.16 & 41.28 & 36.34 & 31.45 & 26.48 \\
\hline 4 & 1.16 & 1.10 & 1.19 & 1.10 & 1.21 & 39.86 & 37.68 & 35.89 & 30.27 & 20.50 \\
\hline \multirow[t]{2}{*}{ Big } & 0.95 & 1.02 & 1.04 & 1.08 & 1.08 & 41.44 & 42.82 & 34.30 & 27.22 & 24.95 \\
\hline & \multicolumn{5}{|c|}{$\beta_{\mathrm{SMB}}$} & \multicolumn{5}{|c|}{$\mathbf{t}\left(\boldsymbol{\beta}_{\mathrm{SMB}}\right)$} \\
\hline Small & 1.43 & 1.03 & 1.03 & 0.92 & 0.99 & 12.50 & 12.63 & 15.98 & 19.40 & 22.34 \\
\hline 2 & 1.08 & 0.94 & 0.92 & 0.90 & 0.99 & 20.60 & 23.25 & 25.96 & 29.92 & 31.02 \\
\hline 3 & 0.93 & 0.85 & 0.81 & 0.84 & 0.94 & 25.02 & 32.59 & 28.00 & 24.07 & 20.56 \\
\hline 4 & 0.66 & 0.61 & 0.59 & 0.53 & 0.77 & 21.19 & 19.36 & 16.46 & 13.44 & 12.15 \\
\hline \multirow[t]{2}{*}{ Big } & -0.14 & -0.02 & -0.04 & -0.01 & 0.01 & -5.72 & -0.85 & -1.09 & -0.30 & 0.31 \\
\hline & \multicolumn{5}{|c|}{$\beta_{\mathrm{HML}}$} & \multicolumn{5}{|c|}{$\mathbf{t}\left(\boldsymbol{\beta}_{\mathrm{HML}}\right)$} \\
\hline Small & 0.14 & -0.37 & 0.06 & 0.23 & 0.53 & 1.02 & -3.95 & 0.79 & 4.23 & 10.24 \\
\hline 2 & -0.23 & 0.08 & 0.14 & 0.42 & 0.67 & -3.72 & 1.73 & 3.38 & 11.96 & 18.01 \\
\hline 3 & -0.20 & 0.05 & 0.34 & 0.51 & 0.90 & -4.58 & 1.57 & 10.08 & 12.40 & 16.88 \\
\hline 4 & -0.24 & 0.24 & 0.43 & 0.50 & 0.80 & -6.69 & 6.56 & 10.33 & 10.97 & 10.95 \\
\hline \multirow[t]{2}{*}{ Big } & -0.45 & -0.01 & 0.28 & 0.47 & 0.81 & -15.64 & -0.37 & 7.36 & 9.39 & 14.99 \\
\hline & \multicolumn{5}{|c|}{$\beta_{\mathrm{NMP}(0)}$} & \multicolumn{5}{|c|}{$\mathbf{t}\left(\boldsymbol{\beta}_{\mathrm{NMP}(0)}\right)$} \\
\hline Small & 0.83 & 0.83 & 0.53 & 0.11 & 0.27 & 3.03 & 4.23 & 3.40 & 0.94 & 2.51 \\
\hline 2 & 0.53 & 0.04 & 0.04 & -0.03 & -0.07 & 4.21 & 0.39 & 0.48 & -0.42 & -0.95 \\
\hline 3 & 0.18 & -0.07 & -0.19 & -0.35 & -0.12 & 2.03 & -1.16 & -2.75 & -4.18 & -1.12 \\
\hline 4 & 0.16 & -0.33 & -0.48 & -0.36 & -0.40 & 2.17 & -4.31 & -5.55 & -3.78 & -2.64 \\
\hline \multirow[t]{2}{*}{ Big } & 0.06 & -0.20 & -0.23 & 0.11 & 0.52 & 1.08 & -3.30 & -2.89 & 1.11 & 4.61 \\
\hline & \multicolumn{5}{|c|}{$\boldsymbol{\beta}_{\mathrm{DE}(\mathbf{0})}$} & \multicolumn{5}{|c|}{$\mathbf{t}\left(\boldsymbol{\beta}_{\mathrm{DE}(\mathbf{O})}\right)$} \\
\hline Small & -0.31 & -2.29 & -1.63 & 3.89 & 2.80 & -1.46 & -2.29 & -1.63 & 3.89 & 2.80 \\
\hline 2 & -0.53 & -0.22 & 0.01 & 0.06 & 0.33 & -5.46 & -2.91 & 0.09 & 1.13 & 5.67 \\
\hline 3 & -0.48 & -0.19 & 0.03 & 0.34 & 0.26 & -7.03 & -3.87 & 0.59 & 5.19 & 3.08 \\
\hline 4 & -0.49 & 0.11 & 0.25 & 0.32 & 0.52 & -8.52 & 1.89 & 3.79 & 4.47 & 4.45 \\
\hline Big & 0.07 & 0.20 & 0.29 & -0.16 & -0.81 & 1.57 & 4.23 & 4.78 & -2.07 & -9.41 \\
\hline \multicolumn{6}{|c|}{ Adjusted R $^{2}$} & & & & & \\
\hline Small & 0.45 & 0.57 & 0.58 & 0.68 & 0.75 & & & & & \\
\hline 2 & 0.77 & 0.78 & 0.81 & 0.86 & 0.86 & & & & & \\
\hline 3 & 0.84 & 0.89 & 0.85 & 0.82 & 0.78 & & & & & \\
\hline 4 & 0.88 & 0.84 & 0.82 & 0.78 & 0.65 & & & & & \\
\hline Big & 0.90 & 0.88 & 0.83 & 0.77 & 0.78 & & & & & \\
\hline
\end{tabular}

The table differs from table 7 in that NMP and DE are formed by single sorts. 


\begin{tabular}{|c|c|c|c|c|c|c|c|c|c|c|}
\hline \multicolumn{11}{|c|}{ B. $R_{\mathrm{it}}-\mathbf{R}_{\mathrm{Ft}}=\beta_{1}+\beta_{\mathrm{RMRF}} \mathrm{RMRF}_{\mathrm{t}}+\beta_{\mathrm{SMB}(0)} \operatorname{SMB}(\mathbf{O})_{\mathrm{t}}+\beta_{\mathrm{HML}(0)} \mathrm{HML}(\mathbf{O})_{\mathrm{t}}+\beta_{\mathrm{NMP}} \mathrm{NMP}_{\mathrm{t}}+\beta_{\mathrm{DE}} \mathrm{DE}_{\mathrm{t}}+\varepsilon_{\mathrm{t}}$} \\
\hline & \multicolumn{10}{|c|}{ Book-to-Market } \\
\hline & Low & 2 & 3 & 4 & High & Low & 2 & 3 & 4 & High \\
\hline & \multicolumn{5}{|c|}{$\beta_{1}$} & \multicolumn{5}{|c|}{$\mathbf{t}\left(\boldsymbol{\beta}_{1}\right)$} \\
\hline Small & 0.85 & 1.11 & 0.54 & 0.43 & 0.17 & 1.94 & 3.57 & 2.17 & 2.39 & 1.03 \\
\hline 2 & 0.43 & -0.09 & 0.10 & -0.09 & -0.40 & 2.17 & -0.60 & 0.74 & -0.81 & -3.33 \\
\hline 3 & 0.03 & -0.14 & -0.08 & -0.16 & 0.03 & 0.22 & -1.38 & -0.69 & -1.19 & 0.18 \\
\hline 4 & 0.02 & -0.35 & -0.42 & -0.02 & -0.13 & 0.14 & -2.95 & -3.06 & -0.13 & -0.55 \\
\hline \multirow[t]{2}{*}{ Big } & 0.07 & -0.18 & -0.16 & 0.02 & 0.51 & 0.75 & -1.87 & -1.27 & 0.14 & 2.88 \\
\hline & \multicolumn{5}{|c|}{$\beta_{\text {RMRF }}$} & \multicolumn{5}{|c|}{$\mathbf{t}\left(\boldsymbol{\beta}_{\mathrm{RMRF}}\right)$} \\
\hline Small & 1.05 & 0.93 & 0.79 & 0.78 & 0.89 & 9.83 & 12.30 & 13.17 & 17.72 & 21.52 \\
\hline 2 & 1.12 & 1.00 & 0.90 & 0.98 & 0.98 & 22.85 & 26.36 & 27.40 & 35.07 & 33.06 \\
\hline 3 & 1.08 & 1.01 & 0.98 & 1.03 & 1.13 & 31.16 & 41.28 & 36.34 & 31.45 & 26.48 \\
\hline 4 & 1.16 & 1.10 & 1.19 & 1.10 & 1.21 & 39.86 & 37.68 & 35.89 & 30.27 & 20.50 \\
\hline \multirow[t]{2}{*}{ Big } & 0.95 & 1.02 & 1.04 & 1.08 & 1.08 & 41.44 & 42.82 & 34.30 & 27.22 & 24.95 \\
\hline & \multicolumn{5}{|c|}{$\beta_{\mathrm{SMB}(0)}$} & \multicolumn{5}{|c|}{$\mathbf{t}\left(\boldsymbol{\beta}_{\mathrm{SMB}(0)}\right)$} \\
\hline Small & 1.29 & 0.89 & 0.94 & 0.81 & 0.86 & 8.91 & 8.72 & 11.54 & 13.45 & 15.38 \\
\hline 2 & 1.07 & 0.99 & 0.91 & 0.89 & 0.92 & 16.19 & 19.27 & 20.26 & 23.47 & 22.94 \\
\hline 3 & 1.00 & 0.92 & 0.85 & 0.85 & 0.91 & 21.37 & 27.79 & 23.31 & 19.23 & 15.69 \\
\hline 4 & 0.75 & 0.67 & 0.65 & 0.54 & 0.74 & 18.81 & 16.78 & 14.41 & 10.88 & 9.30 \\
\hline \multirow[t]{2}{*}{ Big } & -0.18 & -0.02 & -0.05 & 0.00 & 0.08 & -5.64 & -0.57 & -1.17 & -0.03 & 1.40 \\
\hline & \multicolumn{5}{|c|}{$\boldsymbol{\beta}_{\mathrm{HML}(\mathbf{O})}$} & \multicolumn{5}{|c|}{$\mathbf{t}\left(\boldsymbol{\beta}_{\mathrm{HML}(\mathbf{O})}\right)$} \\
\hline Small & 0.24 & -0.25 & 0.12 & 0.03 & 0.37 & 1.33 & -2.00 & 1.23 & 0.42 & 5.44 \\
\hline 2 & 0.03 & 0.20 & 0.13 & 0.39 & 0.48 & 0.32 & 3.21 & 2.41 & 8.27 & 9.82 \\
\hline 3 & 0.06 & 0.16 & 0.34 & 0.35 & 0.76 & 1.03 & 3.95 & 7.54 & 6.38 & 10.74 \\
\hline 4 & 0.02 & 0.21 & 0.33 & 0.35 & 0.55 & 0.43 & 4.25 & 5.95 & 5.74 & 5.58 \\
\hline \multirow[t]{2}{*}{ Big } & -0.49 & -0.11 & 0.14 & 0.55 & 1.23 & -12.94 & -2.68 & 2.70 & 8.29 & 16.96 \\
\hline & \multicolumn{5}{|c|}{$\beta_{\text {NMP }}$} & \multicolumn{5}{|c|}{$\mathbf{t}\left(\boldsymbol{\beta}_{\mathrm{NMP}}\right)$} \\
\hline Small & 1.91 & 1.75 & 1.34 & 0.83 & 0.90 & 8.17 & 10.50 & 10.11 & 8.55 & 9.93 \\
\hline 2 & 1.50 & 0.86 & 0.81 & 0.63 & 0.57 & 13.97 & 10.31 & 11.23 & 10.15 & 8.74 \\
\hline 3 & 1.07 & 0.70 & 0.45 & 0.28 & 0.39 & 14.10 & 13.05 & 7.55 & 3.93 & 4.18 \\
\hline 4 & 0.83 & 0.20 & -0.02 & -0.01 & 0.05 & 13.01 & 3.06 & -0.27 & -0.11 & 0.40 \\
\hline \multirow[t]{2}{*}{ Big } & 0.11 & -0.18 & -0.33 & -0.11 & 0.09 & 2.12 & -3.37 & -4.90 & -1.29 & 0.93 \\
\hline & \multicolumn{5}{|c|}{$\beta_{\mathrm{DE}}$} & \multicolumn{5}{|c|}{$\mathbf{t}\left(\boldsymbol{\beta}_{\mathrm{DE}}\right)$} \\
\hline Small & -0.13 & -4.72 & -1.12 & 5.33 & 8.21 & -0.80 & -4.72 & -1.12 & 5.33 & 8.21 \\
\hline 2 & -0.52 & -0.06 & 0.11 & 0.36 & 0.71 & -6.88 & -1.12 & 2.08 & 8.42 & 15.63 \\
\hline 3 & -0.44 & -0.07 & 0.29 & 0.60 & 0.86 & -8.33 & -1.77 & 7.10 & 12.08 & 13.09 \\
\hline 4 & -0.48 & 0.27 & 0.50 & 0.59 & 0.94 & -10.76 & 5.99 & 9.93 & 10.64 & 10.49 \\
\hline Big & -0.32 & 0.12 & 0.39 & 0.27 & 0.15 & -9.00 & 3.20 & 8.50 & 4.40 & 2.30 \\
\hline \multicolumn{6}{|c|}{ Adjusted $\mathrm{R}^{2}$} & & & & & \\
\hline Small & 0.45 & 0.57 & 0.58 & 0.68 & 0.75 & & & & & \\
\hline 2 & 0.77 & 0.78 & 0.81 & 0.86 & 0.86 & & & & & \\
\hline 3 & 0.84 & 0.89 & 0.85 & 0.82 & 0.78 & & & & & \\
\hline 4 & 0.88 & 0.84 & 0.82 & 0.78 & 0.65 & & & & & \\
\hline Big & 0.90 & 0.88 & 0.83 & 0.77 & 0.78 & & & & & \\
\hline
\end{tabular}

GRS F $1.96=(p-$ value $=0.005)$ 
Table 8A: Summary statistics of different models

\begin{tabular}{lcccccc}
\hline & $\bar{\alpha}(\%)$ & $|\bar{\alpha}|(\%)$ & $\mathrm{RMSE}(\%)$ & $\operatorname{Min}(\%)$ & $\operatorname{Max}(\%)$ & Average $^{2}$ \\
\hline CAPM & 0.39 & 0.42 & 0.51 & -0.19 & 1.00 & 0.48 \\
FF three-factor & 0.06 & 0.18 & 0.24 & -0.32 & 0.73 & 0.76 \\
FS three-factor & 0.47 & 0.50 & 0.63 & -0.14 & 1.57 & 0.59 \\
Five factor & 0.08 & 0.23 & 0.34 & -0.35 & 0.99 & 0.77 \\
FS three-factor2 & 0.50 & 0.53 & 0.69 & -0.19 & 1.66 & 0.61 \\
Five factor2 & 0.08 & 0.26 & 0.38 & -0.42 & 1.11 & 0.06 \\
\hline
\end{tabular}

The table presents the average pricing error $(\bar{\alpha})$, average absolute pricing error $(|\bar{\alpha}|)$, root mean squared pricing error (RMSE), minimum and maximum pricing errors and average adjusted $R^{2}$. CAPM refers to the single factor regressions in table 4 , FF threefactor refers to the regressions in table 5, FS three-factor refers to the regressions in table 6, and Five factor refers to the regressions in table 7. FS three-factor 2 refers to the regressions in table 6A, and Five factor2 refers to the regressions in table 7A. 